\title{
Development of HyPEP, A Hydrogen Production Plant Efficiency Calculation Program
}

C. H. Oh, INL

C. B. Davis, INL

S. R. Sherman, INL

R. Vilim, ANL

Y. J. Lee, KAERI

W. J. Lee, KAERI

March 2006

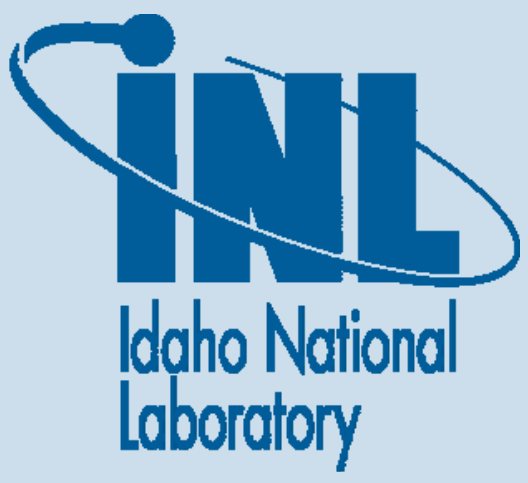

The INL is a U.S. Department of Energy National Laboratory operated by Battelle Energy Alliance 


\title{
Development of HyPEP, A Hydrogen Production Plant Efficiency Calculation Program
}

\author{
C. H. Oh, INL \\ C. B. Davis, INL \\ S. R. Sherman, INL \\ R. Vilim, ANL \\ Y. J. Lee, KAERI \\ W. J. Lee, KAERI \\ March 2006

\begin{abstract}
Idaho National Laboratory
Idaho Falls, Idaho 83415
\end{abstract}




\begin{abstract}
The Department of Energy envisions the next generation very hightemperature gas-cooled reactor (VHTR) as a single-purpose or dual-purpose facility that produces hydrogen and electricity. The Ministry of Science and Technology (MOST) of the Republic of Korea also selected VHTR for the Nuclear Hydrogen Development and Demonstration (NHDD) Project. The report will address the evaluation of hydrogen and electricity production cycle efficiencies for such systems as the VHTR and NHDD, and the optimization of system configurations.

Optimization of such complex systems as VHTR and NHDD will require a large number of calculations involving a large number of operating parameter variations and many different system configurations. The research will produce (a) the HyPEP which is specifically designed to be an easy-to-use and fast running tool for the hydrogen and electricity production evaluation with flexible system layout, (b) thermal hydraulic calculations using reference design, (c) verification and validation of numerical tools used in this study, (d) transient analyses during start-up operation and off-normal operation. This project will also produce preliminary cost estimates of the major components.
\end{abstract}




\section{CONTENTS}

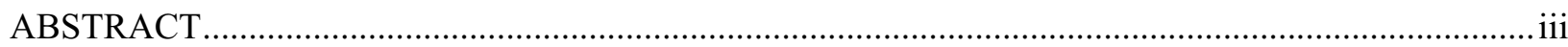

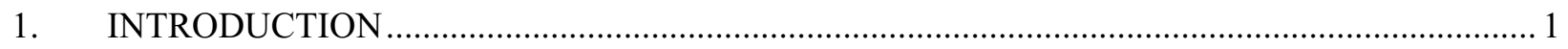

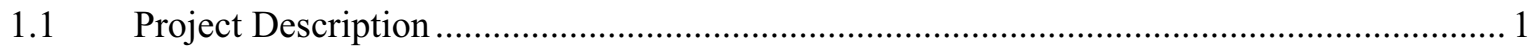

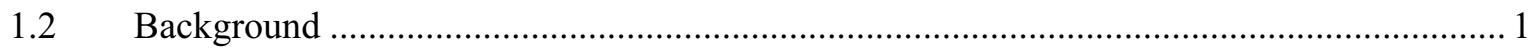

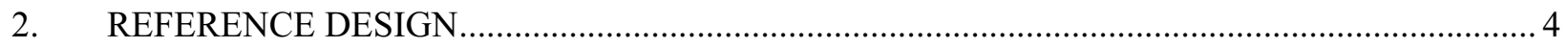

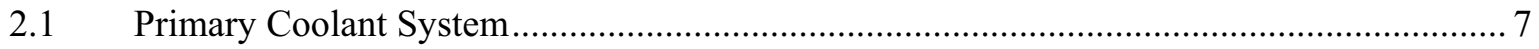

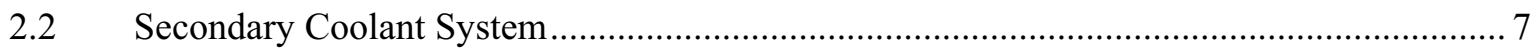

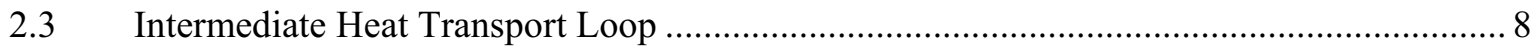

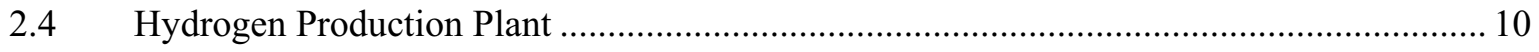

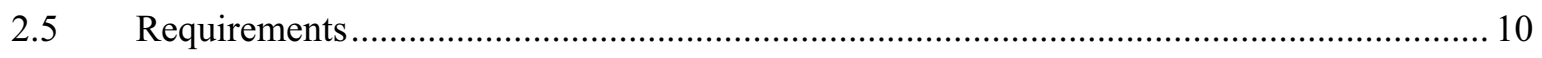

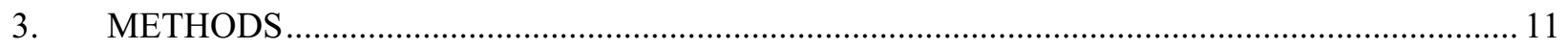

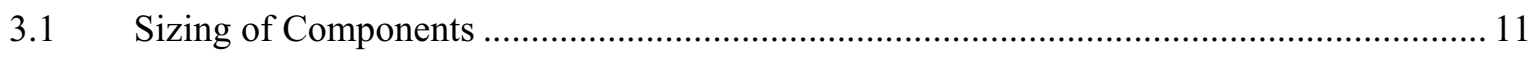

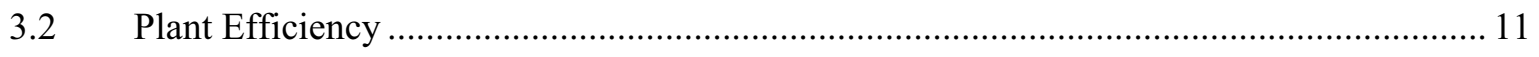

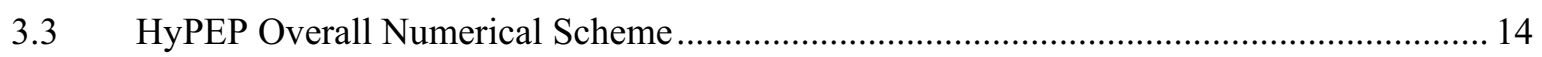

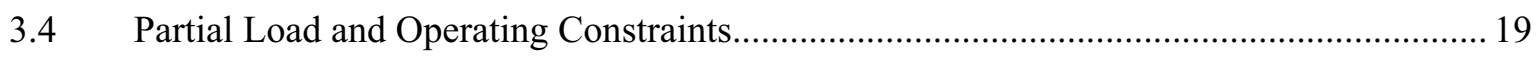

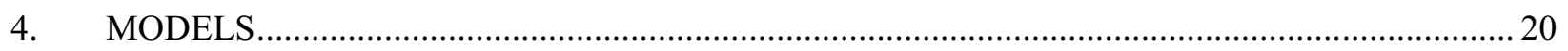

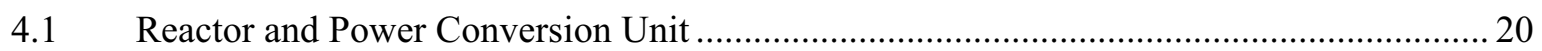

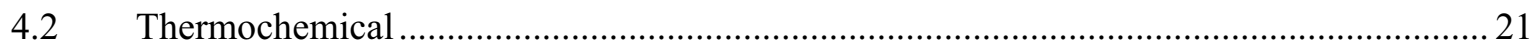

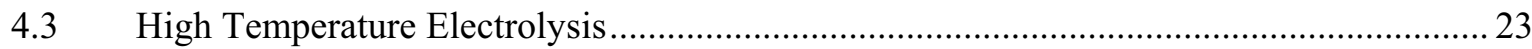

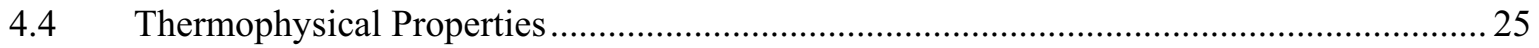

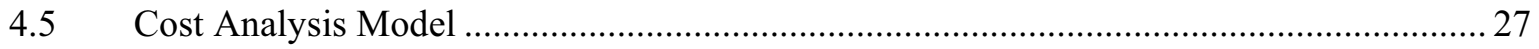

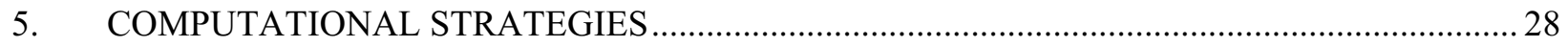

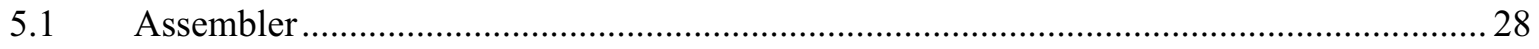

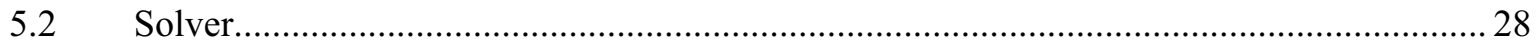

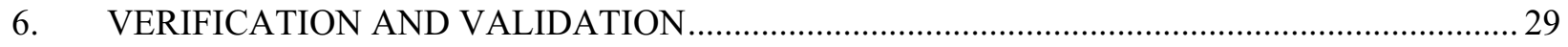




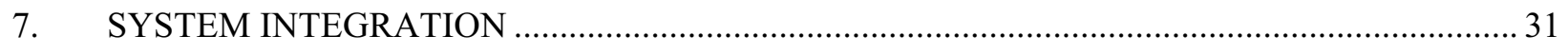

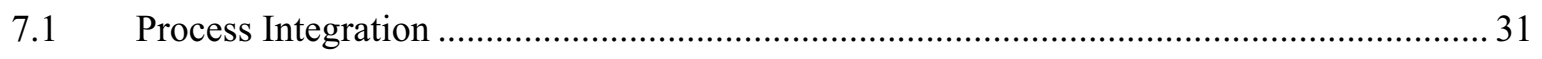

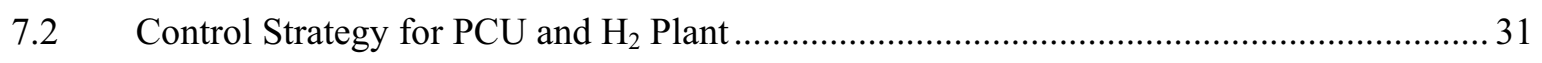

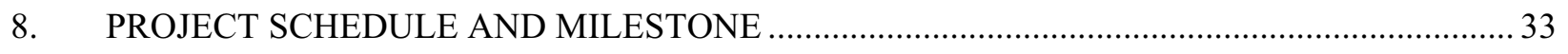

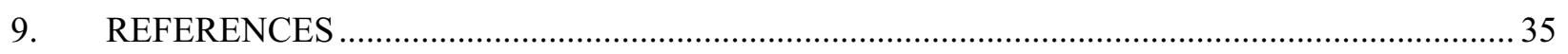

Appendix A —-Lumped Parameter Representation of Sulfur Iodine Process …....................................... 37

FIGURES

1. Potential Layout of VHTR for Hydrogen Production. ................................................................... 2

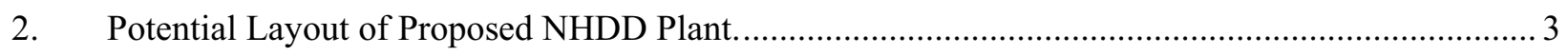

3. Schematic of the reference design of the integrated nuclear and hydrogen production

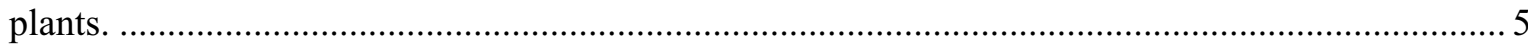

4. Schematic of the alternative reference design of the integrated nuclear and hydrogen

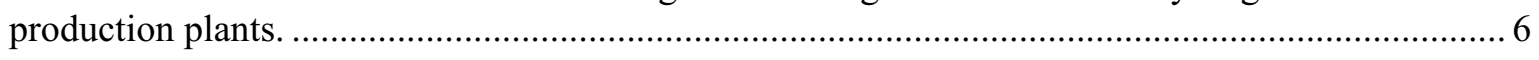

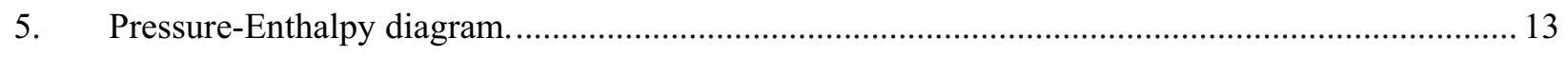

6. T-S diagram for isentropic and polytropic (real) compression................................................. 13

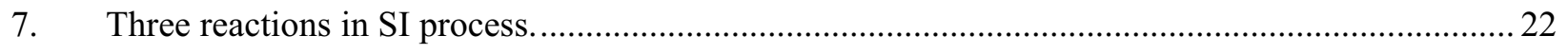

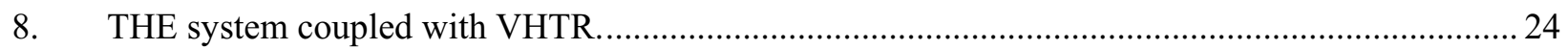

9. Schematic of Main Components in High Temperature Steam Electrolysis Process. ...................... 26

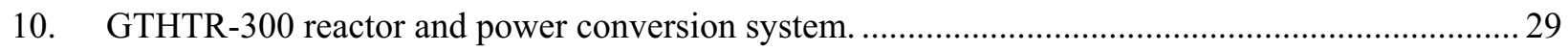

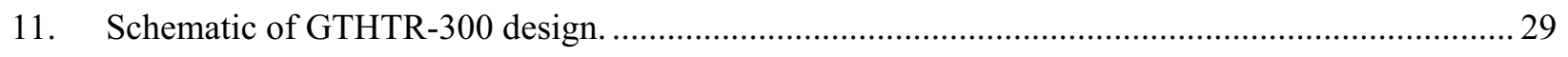

12. Cycle efficiency as a function of reactor inlet temperature .......................................................... 30

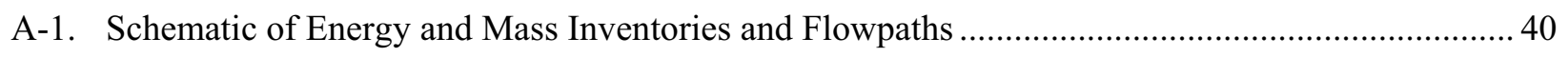

\section{TABLES}

1. Thermal-hydraulic parameters assumed for the primary coolant system. …................................ 7

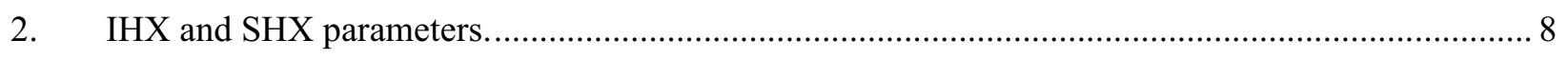

3. Intermediate heat transport loop piping parameters. ….............................................................. 9

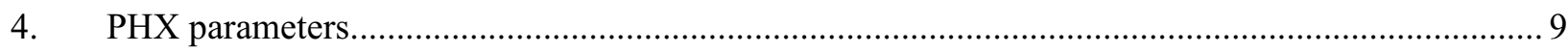




\section{Development of HyPEP, A Hydrogen Production Plant Efficiency Calculation Program}

\section{INTRODUCTION}

\subsection{Project Description}

The Department of Energy envisions the next generation very high-temperature gas-cooled reactor (VHTR) as a single-purpose or dual-purpose facility that produces hydrogen and electricity. The Ministry of Science and Technology (MOST) of the Republic of Korea (ROK) also selected VHTR for the Nuclear Hydrogen Development and Demonstration (NHDD) Project.

The objective of the FY-06 study is (1) to select a reference design that links the reactor, a power conversion system and hydrogen process through an intermediate heat transfer loop (2) to identify key requirements and assumptions, (3) to define methods to be used, (4) to provide ROK collaborators with detailed models of system components such as heat exchanger and others with appropriate heat transfer correlations for their HyPEP development.

HyPEP computer program will have the capability to model and to calculate the electrical generation efficiencies of a Brayton or Rankine cycle, and the hydrogen production efficiencies of the high temperature electrolysis and the S-I thermo-chemical cycles. The primary application of HyPEP will be for the VHTR (Very High Temperature Reactor) coupled to hydrogen production plants such as NHDD. The principal applications for HyPEP are in the scoping analyses on plant configurations, and the optimizations on various design and operating parameters. HyPEP will be developed to run under the PCWindows environment and will use the Graphic User Interface (GUI) extensively to enhance user friendliness. HyPEP will be available to support analyses for both the United States and Korean governments.

\subsection{Background}

The abundant cheap fossil energy resources such as oil and coal fuelled the great technological advances of the $19^{\text {th }}$ and $20^{\text {th }}$ that have dramatically improved the quality of human life. However, the massive use of fossil fuels has brought serious problems in pollution and global warming. In particular, if the current rate of oil usage is continued, the oil is forecasted to be depleted in the $21^{\text {st }}$ century. The supply of high quality energy at a reasonable price is essential to maintain and improve the quality of life, and there is an urgent need to develop energy resources to replace oil.

Hydrogen is being promoted as the future energy-carrier under the proposed "hydrogen economy" scheme. Hydrogen is proposed to replace oil primarily in the transportation sector. Hydrogen may be burned in an Internal Combustion Engine (ICE) or oxidized in fuel cells to provide the motive power. Hydrogen is environmentally clean as the byproduct of hydrogen burn or oxidation is pure water. Although hydrogen is the most abundant element in the universe, hydrogen in molecular form $\left(\mathrm{H}_{2}\right)$ does not exist in appreciable quantities on earth. Thus, it is necessary to produce molecular hydrogen from base materials such as water or methane using energy from such primary sources as coal, solar, wind or nuclear energy.

The Nuclear Hydrogen Initiative (NHI) calls for the demonstration of hydrogen production technologies utilizing nuclear energy. The goal is to demonstrate hydrogen production compatible with nuclear energy systems by way of scaled demonstrations, and then to couple a commercial-sized 
demonstration plant with a Generation IV demonstration facility by approximately 2015 . The process of producing the hydrogen from water is highly energy intensive and the efficiency of the process depends on different factors for different processes. The high temperature electrolysis and the thermo-chemical cycles can produce hydrogen from water and these processes are being developed.

For the demonstration of hydrogen generation using nuclear power, the INL (Idaho National Laboratory) in the US, and KAERI (Korea Atomic Energy Research Institute) in the Republic of Korea have proposed the developments of the VHTR (Very High Temperature Reactor) and the NHDD (Nuclear Hydrogen Development and Demonstration), respectively. The potential layouts of the VHTR and NHDD are shown in Figure 1 and Figure 2.

Both plants use the VHTR (Very High Temperature Reactor) to supply the power, while they are designed to use two different hydrogen production processes; the high temperature electrolysis and the I-S thermo-chemical process. The VHTR is used because the high temperature is essential in maximizing the hydrogen production efficiencies for both electrolysis and the thermo-chemical process.

In order to optimize the designs of such plant systems as VHTR and NHDD, it is necessary to be able to evaluate the operating parameters and production efficiencies of various design layouts. The presently proposed project aims to develop a computer program HyPEP to easily and quickly evaluate the efficiencies and operating parameters.

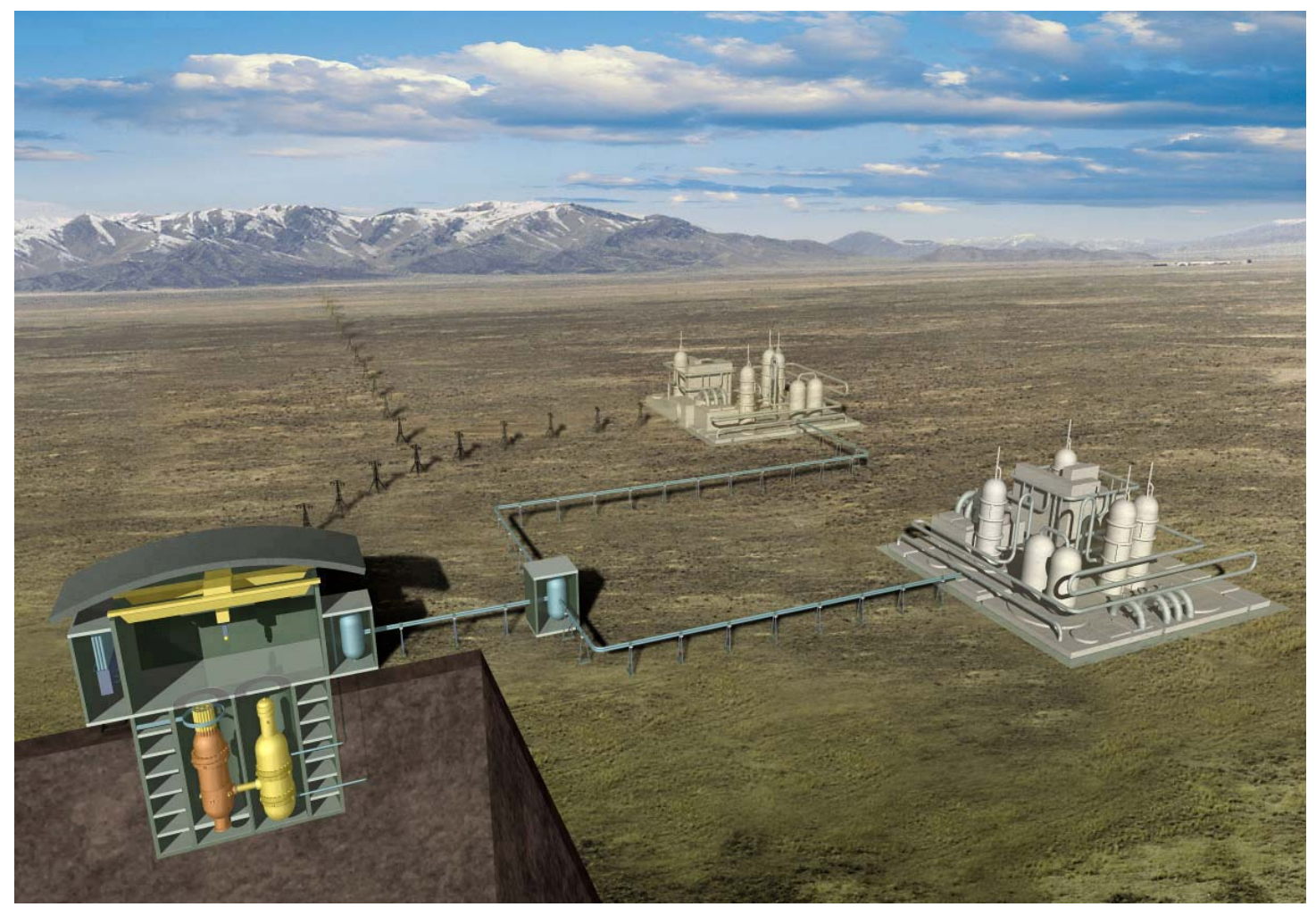

Figure 1. Potential Layout of VHTR for Hydrogen Production. 


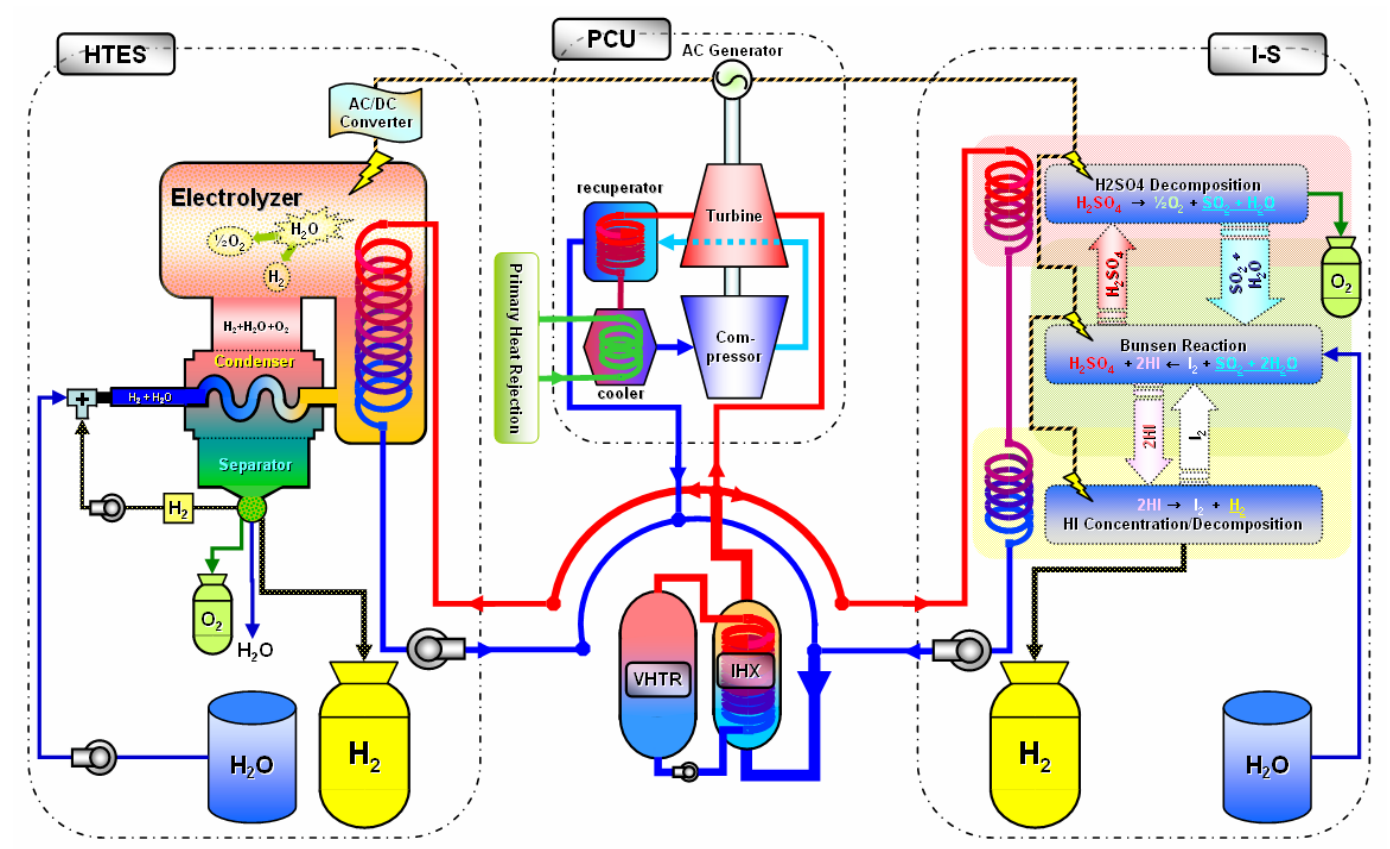

Figure 2. Potential Layout of Proposed NHDD Plant. 


\section{REFERENCE DESIGN}

A reference design of a coupled nuclear reactor and hydrogen production plant has been established to aid in the development of HyPEP. The reference design incorporates many of the systems and components that HyPEP must eventually be able to model. The reference design is expected to be representative of the eventual design and will be used to focus the development of HyPEP. The reference design has not been optimized and many changes are expected between the concept described here and any design ultimately selected for hydrogen production.

The reference design contains a high-temperature gas-cooled reactor that is used simultaneously for the production of electricity and hydrogen. Less than $10 \%$ of the nuclear reactor's thermal energy is dedicated to hydrogen production, consistent with that expected in early demonstration plants, such as the Next Generation Nuclear Plant (NGNP) (MacDonald et al. 2003). The power conversion unit (PCU) utilizes an indirect electrical cycle based on the recommendations of the Independent Technology Review Group (2004) for the NGNP. An intermediate heat transport loop is used to transfer heat from the nuclear reactor to the hydrogen production plant and to provide separation between the nuclear and hydrogen plants. Helium is used as a working fluid in both the secondary coolant system and the intermediate heat transport loop. The hydrogen production process is based on the thermochemical sulfur-iodine cycle described by Brown et al. (2003). A schematic of the reference design is illustrated in Figure 3. Various systems are described in more detail below.

An alternative design is the high temperature electrolysis process (HTE). GA report (2002) indicates that due to lack of thermodynamic models, GA was not able to regress the simple $\mathrm{H}_{2} \mathrm{SO} 4 / \mathrm{H}_{2} \mathrm{O}$ and GA did not even attempt to regress more complicated systems of $\mathrm{HI} / \mathrm{I}_{2} / \mathrm{H}_{2} \mathrm{O}$ along with $\mathrm{H}_{2} \mathrm{SO}_{4} / \mathrm{HI} / \mathrm{I}_{2} / \mathrm{H}_{2} \mathrm{O}$ in the $\mathrm{S}-\mathrm{I}$ thermo chemical process.

Therefore, until the thermodynamic model is developed, the full-detailed ASPEN PLUS model on the S-I process is not accurate when the ASPEN's ELECNRTL thermodynamic model is used. Without the thermodynamic model, HYSYS cannot be used for the S-I process model either. However, instead of the detailed S-I and/or HTE model, we can use simplified block models shown in Figure 3 and Figure 4. The simplified blocks represent major components in the S-I process or HTE process and we count for only energy and mass balance around it.

The HTE process is simpler than that of S-I process. Therefore, eventually the detailed model of the HTE can be developed starting next year. The detailed model was not included in the original proposal. In order to evaluate the potential hydrogen production performance of large-scale HTE operations, INL has developed a detailed process flowsheet that includes all of the components that would be present in an actual plant such as pumps, compressors, heat exchangers, turbines, and the electrolyzer. Since the electrolyzer is not a standard HYSYS component, a custom one-dimensional electrolyzer model will be developed and optimized for incorporation into the overall HYSYS process flowsheet. This electrolyzer model allows for the determination of the operating voltage, gas outlet temperatures, and electrolyzer efficiency for any specified inlet gas flow rates, current density, cell active area, and external heat loss or gain. Then the model will be incorporated into the reference design and the entire detailed major component sizing calculations can be performed. 


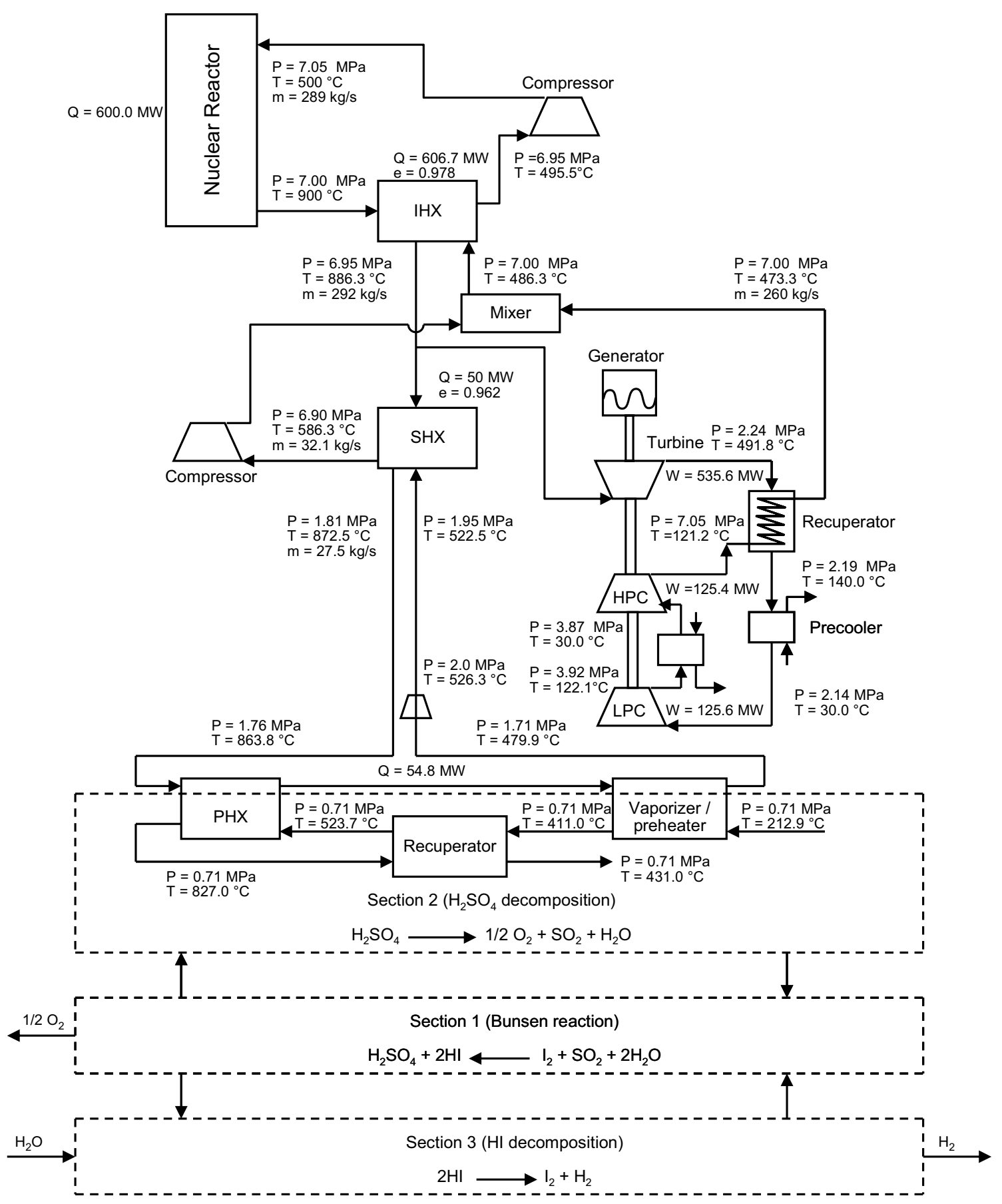

Figure 3. Schematic of the reference design of the integrated nuclear and hydrogen production plants. 


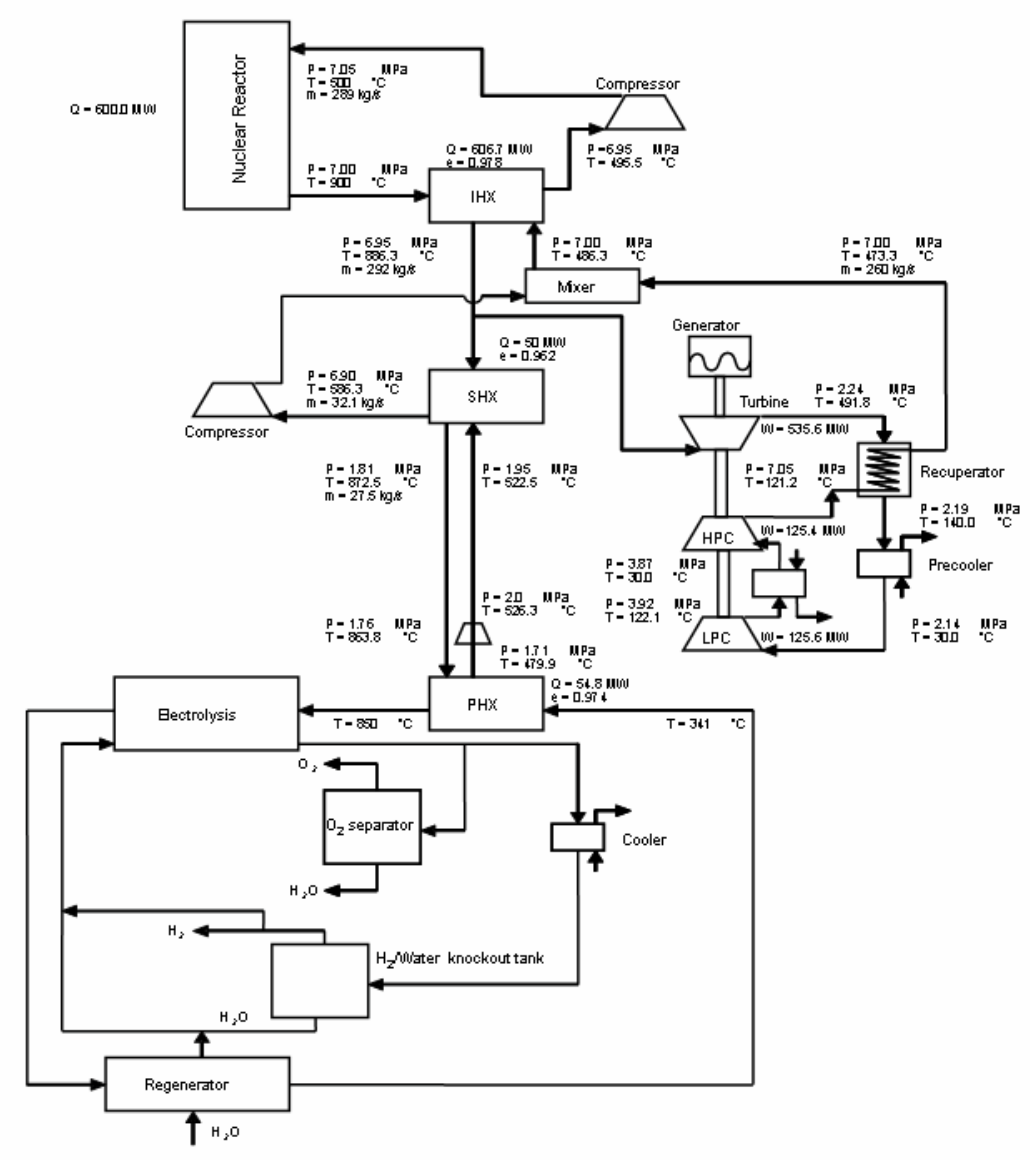

Figure 4. Schematic of the alternative reference design of the integrated nuclear and hydrogen production plants.

The working fluid selection affects the cycle operating condition, the efficiency, and the size of the unit-operation components, which will be a major factor for the system cost. Some fluids such as $\mathrm{CO}_{2}$ are not recommended for use in the direct cycle due to chemical reactions with the graphite matrix in the VHTR core at temperatures greater than $550^{\circ} \mathrm{C}$, due to heat transfer, neutronics impacts, or activation concerns. For the indirect cycles, there exists a freedom to examine a number of working fluids. These coolants will be examined to see if they provide improved efficiency, cost reduction or reduced development risk when compared to a baseline cycle.

For this study, the following working fluids will be investigated:

- $\quad$ Helium in the primary, the secondary, and the tertiary loop.

- Molten salts in the primary and the tertiary loop

- $\mathrm{CO}_{2}$ in the secondary and tertiary loop.

A number of the power conversion unit (PCU) will be studied to determine if the best overall configuration can be found. The PCU configurations to be examined are a recuperated gas Brayton cycle and recuperated combined cycle. 


\subsection{Primary Coolant System}

The primary coolant system is assumed to consist of a nuclear reactor, an intermediate heat exchanger, and a circulator. The nuclear reactor is assumed to be a high-temperature helium-cooled reactor. The reactor core is assumed to contain prismatic fuel blocks similar to those in the Gas TurbineModular Helium Reactor (GT-MHR) (General Atomics 1996). Because of the expected simplicity of the HyPEP reactor model, a pebble bed reactor could be simulated by changing the pressure drop across the core.

The assumed thermal-hydraulic parameters for the primary coolant system are described by Davis et al. (2005) and are summarized in Table 1.

Table 1. Thermal-hydraulic parameters assumed for the primary coolant system.

\begin{tabular}{|l|c|}
\hline \multicolumn{1}{|c|}{ Parameter } & Value \\
\hline Coolant & Helium \\
\hline Pressure, $\mathrm{MPa}$ & 7.0 \\
\hline Power, $\mathrm{MW}$ & 600 \\
\hline Outlet temperature, ${ }^{\circ} \mathrm{C}$ & 900 \\
\hline Temperature rise, ${ }^{\circ} \mathrm{C}$ & 400 \\
\hline Differential pressure, $\mathrm{MPa}:$ & \\
\hline Core & 0.05 \\
\hline IHX & 0.05 \\
\hline
\end{tabular}

\subsection{Secondary Coolant System}

The secondary coolant system of the reference design consists of a PCU that is arranged in parallel with a secondary heat exchanger (SHX) that directs less than $10 \%$ of the reactor power towards the hydrogen production plant. This arrangement corresponds to Configuration 6 recommended by Davis et al. (2005) for an indirect electrical cycle.

The PCU contains a turbine, two compressors, and an electrical generator that are located on a single shaft. The PCU also contains a recuperator, precooler, and another cooler located between the low pressure compressor (LPC) and the high pressure compressor (HPC). Two compressors and coolers are used to improve the efficiency of the electrical cycle. The thermodynamic states at various locations in the PCU were determined by Davis et al. (2005) and are summarized in Figure 3. The PCU heat exchangers were not sized. Although Davis et al. made assumptions concerning their performance, the actual geometries of the heat exchangers were not determined.

The IHX and SHX are assumed to be printed circuit heat exchangers (PCHEs) with straight semicircular flow channels. The flow channels are contained within plates. Half of the plates are assumed to contain hot fluid, while the others contain cold fluid. The flow path is characterized by the diameter of the semi-circular channels, the pitch between adjacent channels in a plate, and the thickness of the plate. Davis et al. (2005) assumed a channel diameter of $1.5 \mathrm{~mm}$ and estimated the pitch-to-diameter and thickness-to-diameter ratios based on a simplified stress analysis. Although more rigorous stress calculations would probably result in larger ratios, these estimates are considered to be sufficiently representative to be used in the reference design. These inputs can be easily changed in HyPEP once 
better data become available. Davis et al. adjusted the width of the front face of the heat exchangers, which were assumed to be square, and the channel length to obtain the desired pressure drop in the hot fluid and thermal performance. The resulting geometries of the IHX and SHX are summarized in Table 2. Thermodynamic states were shown previously in Figure 3.

Table 2. IHX and SHX parameters.

\begin{tabular}{|l|l|l|}
\hline \multicolumn{1}{|c|}{ Parameter } & \multicolumn{1}{c|}{ IHX } & \multicolumn{1}{c|}{ SHX } \\
\hline Nominal power, MW & 600 & 50 \\
\hline Differential pressure (hot / cold), MPa & $0.050 / 0.050$ & $0.050 / 0.14$ \\
\hline Heat exchanger width, m & 4.77 & 1.51 \\
\hline Flow channels: & & \\
\hline Diameter, mm & 1.5 & 1.5 \\
\hline Pitch-to-diameter ratio & 1.20 & 1.5 \\
\hline Thickness-to-diameter ratio & 0.57 & 0.78 \\
\hline Length & 2.26 & 1.11 \\
\hline
\end{tabular}

HyPEP should be flexible enough to accommodate alternate PCHE designs. Specifically, the options to account for zigzag, rather than straight, flow channels and different numbers of hot and cold plates should be allowed. For example, Ishizuka et al. (2005) measured pressure drop and heat transfer data for a PCHE in which the flow channels had zigzags. The PCHE also had half as many cold plates as hot plates. These modifications result in a more compact, and presumably cheaper, heat exchanger than would be obtained otherwise. It is likely that the eventual design will incorporate similar modifications to enhance the heat transfer and reduce the size of the heat exchangers.

\subsection{Intermediate Heat Transport Loop}

The intermediate heat transport loop transfers heat from the nuclear reactor to the hydrogen production plant and provides physical separation between plants, which should make the nuclear plant easier to license. Estimates for the required separation distance between the nuclear and hydrogen plants depend on the design and safety criteria applied and vary considerably. For example, Verfondern and Nishihara (2004) calculated $300 \mathrm{~m}$ for the High-Temperature Engineering Test Reactor in Japan whereas Sochet et al. (2004) recommended $500 \mathrm{~m}$ for the High-Temperature Reactor. Smith et al. (2005) recommended a separation distance of from 60 to $120 \mathrm{~m}$ for the NGNP and the hydrogen production plant. A separation distance of $90 \mathrm{~m}$ is used for the reference design based on the value selected by Davis et al. (2005). The separation distance primarily affects the diameters and insulation requirements of the hot and cold legs in the heat transport loop.

Based on the analysis of Davis et al. (2005), the hot and cold legs of the intermediate loop are assumed to be separate pipes in the reference design. To limit stresses, the working fluid is assumed to be low-pressure helium as shown in Figure 3.

Table 3 provides parameters for the piping of the intermediate heat transport loop. These parameters are based on the analysis of Davis et al. (2005). Thermodynamic states are presented in Figure 3. 
Table 3. Intermediate heat transport loop piping parameters.

\begin{tabular}{|l|l|l|}
\hline \multicolumn{1}{|c|}{ Parameter } & \multicolumn{1}{c|}{ Hot leg } & \multicolumn{1}{c|}{ Cold leg } \\
\hline Differential pressure, MPa & 0.050 & 0.050 \\
\hline Heat loss, MW & 1.25 & 0.54 \\
\hline Length, $\mathrm{m}$ & 90 & 90 \\
\hline Inner diameter, m & 0.443 & 0.412 \\
\hline Pipe thickness-to-diameter ratio & 0.11 & 0.01 \\
\hline
\end{tabular}

Liquid salts are more efficient for transporting heat over long distances than helium and thus may ultimately be selected as the working fluid. Therefore, HyPEP should have the capability to simulate liquid salts as potential working fluids.

The intermediate heat transport loop is assumed to be coupled to the hydrogen production plant through two heat exchangers as shown in Figure 3. The first heat exchanger preheats and partially vaporizes the $\mathrm{H}_{2} \mathrm{SO}_{4} / \mathrm{H}_{2} \mathrm{O}$ mixture. The mixture is fully vaporized by a recuperator that is located entirely within the hydrogen production plant. The mixture is then heated up to its maximal temperature by a process heat exchanger (PHX) that takes heat from the intermediate heat transport loop. The thermodynamic conditions given in Figure 3 on the hot side of the preheater/vaporizer and the PHX were taken from the values given by Davis et al. (2005). The thermodynamic conditions on the cold side of these heat exchangers were based on the values given by Brown et al. (2003).

Davis et al. (2005) assumed that the PHX was a tube-in-shell heat exchanger, with the process fluid on the tube side. Brown et al. (2003) assumed that the PHX was a PCHE. Lillo et al. (2005) did a simple analysis comparing the relative surface area required for the catalyst versus that required for heat transfer. For the tube-in-shell heat exchanger, the catalytic size requirements were somewhat more limiting that the thermal requirements. For the PCHE, the size was definitely controlled by the catalytic requirements. In fact, for reasonable channel diameters, the PCHE was actually larger than the tube-in-shell heat exchanger. Thus, a tube-in-shell heat exchanger was selected for the PHX in the reference design. HyPEP needs to have the capability to model tube-in-shell heat exchangers anyway because this type of exchanger is common in PCUs and chemical plants.

PHX parameters are summarized in Table 4. These parameters are based the values given by Davis et al. (2005). Note that the specification of PHX parameters is incomplete because the PHX has not yet been sized to meet the thermal and catalytic requirements for coupling the intermediate heat transport loop to the hydrogen production plant.

Table 4. PHX parameters.

\begin{tabular}{|l|l|}
\hline \multicolumn{1}{|c|}{ Parameter } & \multicolumn{1}{c|}{ Value } \\
\hline Tube inner diameter, $\mathrm{cm}$ & 1.0 \\
\hline Tube thickness-to-inner diameter ratio & 0.15 \\
\hline Tube pitch-to-outer diameter ratio & 1.3 \\
\hline Tube pitch & Triangular \\
\hline
\end{tabular}

Parameters for the preheater/vaporizer are not yet available. For the purposes of the reference design, any configuration that results in thermodynamic states at the inlet of the PHX and the outlet of the preheater/vaporizer on the hot side and the inlet of the preheater/vaporizer and the outlet of the PHX on the process side would be acceptable. 


\subsection{Hydrogen Production Plant}

The hydrogen production process in the reference design is based on the thermochemical sulfuriodine cycle described by Brown et al. (2003). As illustrated in Figure 3, the cycle is represented by three sections. The first section represents the Bunsen reaction, which generates sulfuric and hydroic acids and produces oxygen. The second section receives heat from the intermediate heat transport loop to concentrate and decompose the sulfuric acid. The third section, which receives distilled water as a feedstock, decomposes the hydrogen iodide and produces hydrogen.

General Atomics has been working on improving the thermochemical cycle. A report describing the improved cycle is expected in April of 2006. It is expected that the thermochemical portion of the reference design will be revised once the new results from General Atomics are available.

\subsection{Requirements}

The selection of the reference and alternative designs imposes requirements that HyPEP must satisfy if it is to be capable of representing the combined nuclear, PCU, and hydrogen plants. These requirements are related to the working fluids, components, and phenomena that must be modeled. The working fluids, components, phenomena associated with the reference design should have the highest priority for HyPEP development. The fluids, components, and phenomena associated with the alternate designs can be added as needed or as time becomes available.

HyPEP must be able to simulate many different fluids to represent the combined plant. For the reference design, these fluids include helium, sulfuric acid, water, hydrogen iodine, iodine, and hydrogen. HyPEP must be able to simulate mixtures in which the concentrations of the various components vary as a function of position to represent the thermochemical cycle. HyPEP needs to simulate additional fluids to represent the alternative designs. These fluids for the IHTC include supercritical carbon dioxide, nitrogen, and liquid salts.

The reference design contains the following components: a nuclear reactor, heat exchangers, compressors, pumps, turbines, generators, separators, scrubbers, and other specialized equipment used in chemical plants. The reference design includes PCHE and tube-in-shell heat exchangers. Alternate heat exchangers, such as an offset strip fin type, probably need to be considered.

HyPEP should model various phenomena associated with the components described above. Descriptions of important phenomena that HyPEP must simulate are provided below.

Nuclear reactor: The nuclear reactor will be modeled simply as a heat source with a specified flow and pressure drop. The effects of these parameters on the overall efficiency of the plant need to be accounted for, but internal details, such as fuel temperature, do not need to be simulated.

Turbomachinery: The most important phenomenon associated with these components is efficiency. In order to perform optimization studies, HyPEP should be able to determine efficiency and head as a function of flow and temperature.

Heat exchangers: Two important parameters associated with these components are heat transfer and pressure drop. To simulate the heat transfer, HyPEP must be able to simulate the thermal resistances associated with convection and heat conduction. The model should be able to account for the effects of wavy channels in the PCHE on heat transfer and pressure drop. Either laminar or turbulent flow conditions may occur. Multi-node models are probably required to represent heat exchangers in which

phase change occurs, such as steam generators, to account for the different heat transfer regimes including forced convection to liquid, nucleate boiling and forced convection to vapor. 


\section{METHODS}

\subsection{Sizing of Components}

The method for sizing heat exchangers is given by Davis et al. (2005). Basically, the method requires the basic geometry to be input. For a PCHE, the basic geometry includes the diameter of the semicircular flow channel, the pitch-to-diameter of the channels, and the plate thickness. Iterations are then performed on the size of the heat exchanger until it provides the desired amount of heat transfer and pressure drop on one side of the heat exchanger.

Pipe components can be sized to produce the desired amount of pressure drop for the given length, flow rate, and thermodynamic conditions in the pipe.

Turbomachinery size can be estimated from the power produced or consumed by the component. Schlenker (1974) suggests that the cost of new turbomachinery can be scaled from the cost of existing machines if the changes in power and operating pressure and temperature are known. Dostal et al. (2004) used this method to estimate the cost for turbomachinery in a Brayton cycle that utilized supercritical carbon dioxide. Thus, the power and operating conditions should also provide an indication of component size.

\subsection{Plant Efficiency}

The efficiency of each proposed configuration was estimated using HYSYS (Aspen Technology 2005a), a process optimization code used in the chemical and oil industries.

The PCU cycle efficiency, $\eta_{\mathrm{PCU}}$, used in this study is defined as:

$\eta_{\mathrm{PCU}}=\frac{\text { Electric power output }}{\text { Reactor thermal power }-\mathrm{H}_{2} \text { process power }}=\frac{\Sigma \mathrm{W}_{\mathrm{T}}-\Sigma \mathrm{W}_{\mathrm{C}}-\mathrm{W}_{\mathrm{S}}-\Sigma \mathrm{W}_{\mathrm{CIR}}}{\mathrm{Q}_{\mathrm{th}}-\mathrm{Q}_{\mathrm{H} 2}}$,

where $\Sigma \mathrm{W}_{\mathrm{T}}$ is the total turbine workload, $\Sigma \mathrm{W}_{\mathrm{C}}$ is the total compressor workload, $\mathrm{W}_{\mathrm{S}}$ is the plant stationary load, $\mathrm{W}_{\mathrm{CIR}}$ is the circulator workload in the primary, intermediate, and, if present, tertiary loops, $\mathrm{Q}_{\mathrm{th}}$ is the reactor thermal power, and $\mathrm{Q}_{\mathrm{H} 2}$ is the power supplied through the PHX to the hydrogen generating plant. For the efficiency calculations, we report the overall cycle efficiency, which is defined as

$\eta_{\text {overall }}=\frac{\Sigma \mathrm{W}_{\mathrm{T}}-\Sigma \mathrm{W}_{\mathrm{C}}-\mathrm{W}_{\mathrm{S}}-\Sigma \mathrm{W}_{\mathrm{CIR}}+\mathrm{Q}_{\mathrm{H} 2}}{\mathrm{Q}_{\mathrm{th}}}$,

where $\Sigma \mathrm{W}_{\mathrm{CIR}}$ includes the circulator workload in the primary, intermediate, and, if present, tertiary loops, for example, recycle pump power, make-up water pump power, $\mathrm{H} 2$ circulator, sweep water circulator, $\mathrm{W}_{\mathrm{S}}$ includes the power for the electrolysis for HTE process or S-I process, $\mathrm{Q}_{\mathrm{th}}$ is the reactor thermal power, and $\mathrm{Q}_{\mathrm{H} 2}$ is the hydrogen production mass flow rate times the specific energy content of the hydrogen.

The polytropic efficiency, rather than the isentropic efficiency, will be used for representing the efficiency of the turbomachinery. The equations for the expansion and compression processes in a perfect gas are taken from Saravanamuttoo et al. (1996). For an expansion, the efficiency is calculated from 


$$
\frac{T_{0, e x}}{T_{0, \text { in }}}=\left(\frac{P_{0, e x}}{P_{0, \text { in }}}\right)^{\left(\frac{R}{C_{P}} \eta_{p, e}\right)}
$$

where $R$ is the gas constant, $C_{p}$ is the specific heat, $\eta_{p, e}$ is the turbine polytropic efficiency, $T_{0}$ is the stagnation temperature, and $\mathrm{P}_{0}$ is the stagnation pressure. Subscripts $e x$ and in refer to exit gas and inlet gas, respectively. For a compression, the efficiency is calculated from

$$
\left.\frac{T_{0, e x}}{T_{0, i n}}=\left(\frac{P_{0, e x}}{P_{0, i n}}\right)^{\left(\frac{R}{C_{P}} \frac{1}{\eta_{p, c}}\right.}\right)
$$

The adiabatic and polytropic efficiencies are included in the compressor calculations. An isentropic flash $\left(\mathrm{P}_{\text {in }}\right.$ and Entropy $\mathrm{in}_{\text {in }}$ ) is performed internally to obtain the ideal (isentropic) properties.

$$
\text { AdiabaticEff }=\frac{\text { Work Re quired }_{(\text {ideal })}}{\text { Work Re quired }_{(\text {actual })}}=\frac{\left(H_{\text {out }}-H_{\text {in }}\right)_{\text {ideal }}}{\left(H_{\text {out }}-H_{\text {in }}\right)_{\text {actual }}}
$$

$$
\text { PolytropicEff }=\frac{\left[\left(\frac{P_{\text {out }}}{P_{\text {in }}}\right)^{\left(\frac{n-1}{n}\right)}-1\right] \times\left[\left(\frac{n}{(n-1)}\right) \times\left(\frac{k-1}{k}\right)\right]}{\left[\left(\frac{P_{\text {out }}}{P_{\text {in }}}\right)^{\left(\frac{k-1}{k}\right)}-1\right]} \times \text { AdiabaticEff }
$$

$$
n=\frac{\log \left(P_{\text {out }} / P_{\text {in }}\right)}{\log \left(\rho_{\text {out }, \text { actual }} / \rho_{\text {in }}\right)} \quad \text { (3) and } k=\frac{\log \left(P_{\text {out }} / P_{\text {in }}\right)}{\log \left(\rho_{\text {out }, \text { ideal }} / \rho_{\text {in }}\right)}
$$

where Ideal is isentropic ( $100 \%$ efficiency), actual is a given efficiency, $\mathrm{H}$ is mass enthalpy, out is product stream (discharge), in is a feed stream (suction), $\mathrm{p}$ is pressure, MW is molecular weight, $\mathrm{z}$ is compressibility factor, $\rho$ is mass density, $\mathrm{n}$ is polytropic exponent, and $\mathrm{k}$ is isentropic exponent

The adiabatic and polytropic efficiencies are parts of the expander calculations. An isentropic flash $\left(\mathrm{P}_{\text {in }}\right.$ and Entropy $\left.{ }_{\text {in }}\right)$ is performed to obtain the ideal (isentropic) properties. The flash is done internally on the expander fluid. 
PolytropicEff $=\frac{\left[\left(\frac{P_{\text {out }}}{P_{\text {in }}}\right)^{\left(\frac{k-1}{k}\right)}-1\right]}{\left[\left(\frac{P_{\text {out }}}{P_{\text {in }}}\right)^{\left(\frac{n-1}{n}\right)}-1\right] \times\left[\left(\frac{n}{(n-1)}\right) \times\left(\frac{k-1}{k}\right)\right]} \times$ AdiabaticEff

In order to calculate the pressure and temperature at the exit of a polytropic expansion or compression process, pressure-enthalpy (P-H) data from the NIST database (NIST version 7.) can be used. The procedure is described below and depicted in graphical form in Figure 5:

1. Starting Point 1, follow the line of constant entropy to the required discharge pressure of $\mathrm{P}_{2}$, locating the isentropic discharge state point of $2_{\text {is }}$.

2. With these two points located, the differential isentropic enthalpy can be calculated from the following equation:

$$
\Delta \mathrm{h}_{\text {is }}=\mathrm{h}_{2_{\text {is }}}-\mathrm{h}_{1}
$$

3. Calculate the real discharge enthalpy of point 2 using:

$\mathrm{h}_{2}=\frac{\Delta \mathrm{h}_{\text {is }}}{\eta_{\text {is }}}+\mathrm{h}_{1}$

where $\eta_{\text {is }}$ is the isentropic process efficiency. The point 2 is on the same pressure $P_{2}$ line shown on Figure 6. At the point 2, temperature can be obtained on the same temperature isotherm line in Figure 5. The actual discharge temperature can now be obtained from the P-H diagram (GPSA, 1998) or P-H database. The properties of the working fluid can be incorporated as a property look-up table. Pressuretemperature-enthalpy data from the NIST database can be used.

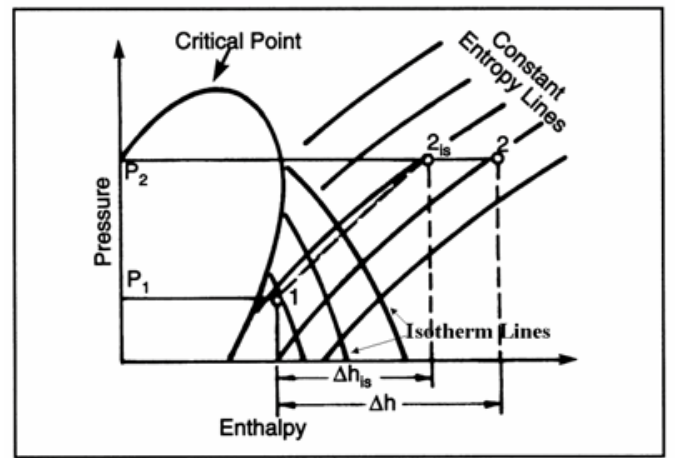

Figure 5. Pressure-Enthalpy diagram.

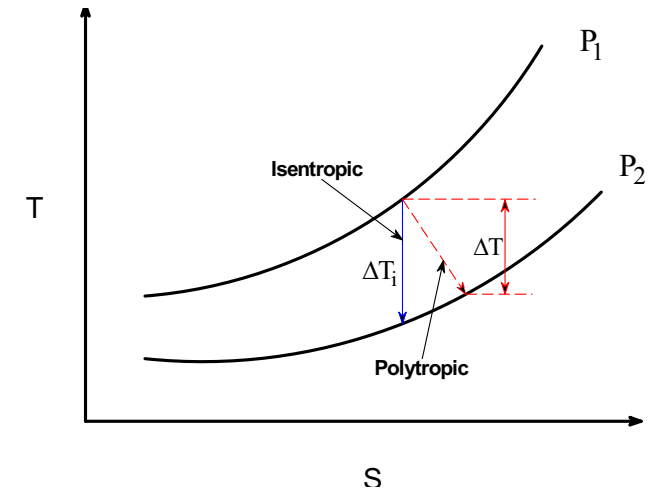

Figure 6. T-S diagram for isentropic and polytropic (real) compression. 
The use of pressure-enthalpy data from the NIST will eliminate problems associated with nonconstant heat capacity term defined in equation (3) and (4) for non-ideal gas such as carbon dioxide at critical condition.

HYSYS was used to develop an input model for each configuration and working fluid and to optimize the cycle efficiency. HYSYS uses the Peng-Robinson (1976) equation of state to determine the properties of the working fluids. However, HYSYS does not have thermal properties for molten salts. Therefore, the physical and thermal properties of Flinak and $\mathrm{NaBF}_{4}-\mathrm{NaF}$ will be input as hypothetical components in tabular form.

The pressure ratio, which is defined as the outlet pressure from the HPC divided by the inlet pressure to the LPC, will be varied to optimize the overall cycle efficiency. Cooling was applied between compressors to reduce the power consumed by the HPC. Cooler components will be used to simulate the heat loss and differential pressure along the hot and cold legs of the intermediate heat transport loop.

\subsection{HyPEP Overall Numerical Scheme}

The thermal hydraulic formulation of the HyPEP will be based on the conservation of mass and energy equations and models for the flow network of multi-species fluid systems. The flow network will be made up of systems and components. For the hydrogen production systems, the HyPEP needs to consider mass and energy conservation of multi-species fluid that undergo chemical reactions. In HyPEP, simplified form of the mass and energy transport equations will be applied for different chemical species.

The node-link-block will be the basic Flow/Heat Network for HyPEP. The node will be used to represent the thermal-hydraulic volume with scalar properties such as volume, mass, molar or mass fraction of fluid specie, energy, pressure, temperature, and pressure drops. The node component will not be designed to handle the chemical reactions. The chemical reaction will be handled by specialized components in HTES and TCS. The link will represent flow between nodes and will have such properties as mass flow rate, pressure drop, and scalar properties of the donor-node. Block component will be used to represent the solid structures that conduct or generate heat. Block component will also provide the solid-to-fluid boundaries where convection occurs.

The basic equations will consider the steady-state mass and energy transport of reactive multispecies fluid mixtures. The equations will be setup to conserve mass and energy. Thermo-dynamic tables for the fluid mixtures will be setup and the procedures for calculating the properties from the table will be devised. Fast and efficient routines will be devised for the property table search. Following fluids will be included as default fluids of HyPEP:

1. Hydrogen

2. Water

3. Steam

4. Oxygen

5. Carbon dioxide

6. Air

7. Nitrogen. 
In addition, to allow user to add fluids, options will be provided for the user to add property tables via external input files.

The node-link-block network scheme and the basic equation setup will be integrated to devise the overall numerical solver scheme. The numerical scheme will be devised to ensure conservation of the mass and energy of the systems and components. The numeric solver will be developed principally for the steady-state operation but with the provisions for further extension to include mild transient calculations.

The flow net of HyPEP will contain all major components associated with the hydrogen generation facility. The user will be able to build the electronic representation of the flow net using the Flow Net Builder which will process the user-specified component data and the boundary conditions.

The Solution Matrix Generator, then, utilizes the electronic flow net and produces the solution matrix which is determined by the discretized form of the flow governing equation. The temporal part of the discretized governing equation will be able to characterize the transient behavior of the flow net. However, for the steady-state condition, the flow net can be solved by using solely the spatial part. The Solution Matrix Generator is able to generate both the temporal and the spatial parts from the information of the electronic flow net. The Flow Net Solver employs solving techniques which can be categorized by: 1) the iteration of the solution matrix 2) the direct inversion of the solution matrix 3 ) the iteration with minor flow modifiers. In general, the flow net can be conveniently solved by using the iterative method when the diagonal dominance is guaranteed.

The diagonal dominance of the solution matrix, therefore, should be checked before choosing the solution strategy. Most of flow net with simple topology will exhibit diagonal dominance. For the flow net of complex topology, the iterative method may not be used. When the solution matrix does not show diagonal dominance, the Solution Strategy Chooser will pick the direct inversion or the iterative method with minor flow modifier.

After all the thermodynamic conditions are calculated, the production and the consumption in each component for hydrogen, electricity and the heat will be evaluated to assess the plant hydrogen production efficiency.

For the FlowNet solver, following method can be adopted as the numerical scheme. For a simple fluid connection layout basic continuity equations are set up :

\section{Mass Continuity (for node)}

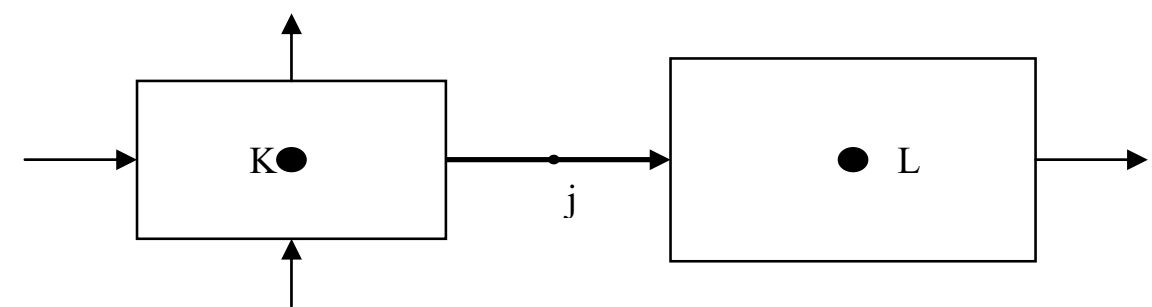

$V \frac{\partial \rho}{\partial t}=\sum_{j=1}^{N_{j}} \widetilde{\rho}_{j} A_{j} u_{j}+S_{m} V$ 


$$
\begin{aligned}
& V \frac{\partial(\rho h)}{\partial t}=\sum_{j=1}^{N_{j}} \widetilde{\rho}_{j} \widetilde{h}_{j} A_{j} u_{j}+S_{h} V \\
& \text { or, } V\left(\rho \frac{\partial h}{\partial t}+h \frac{\partial \rho}{\partial t}\right)=\sum_{j=1}^{N_{j}} \widetilde{\rho}_{j} \widetilde{h}_{j} A_{j} u_{j}+S_{h} V
\end{aligned}
$$

For the consideration of the velocity the simple flow relationship is used rather than the momentum conservation equation. This will simplify the solution method greatly as the detailed considerations of the momentum correlations are not needed.

Flow Relationship (for link i)

$$
f_{T} \frac{\rho u^{2}}{2}=\left(P_{K}-P_{L}\right)+\Delta P_{K, \text { source }}+\Delta P_{\text {extra }}
$$

where

$$
\begin{aligned}
& V=\text { volume of node }\left(\mathrm{m}^{3}\right) \\
& u=\text { fluid velocity }(\mathrm{m} / \mathrm{s}) \\
& \rho=\operatorname{density}\left(\mathrm{kg} / \mathrm{m}^{3}\right) \\
& \widetilde{\rho}=\text { density of donor node }\left(\mathrm{kg} / \mathrm{m}^{3}\right) \\
& h \quad=\text { enthalpy (Joule/ } \mathrm{kg} \text { ) } \\
& \tilde{h}=\text { enthalpy of donor node (Joule } / \mathrm{kg}) \\
& A_{j}=\text { flow area of link }\left(\mathrm{m}^{2}\right) \\
& N_{j}=\text { Total number of links connected to a given node }\left(N_{j}>0\right) \\
& S_{m}=\text { volumetric mass generation rate }\left(\mathrm{kg} / \mathrm{m}^{3} / \mathrm{s}\right) \\
& S_{h}=\text { volumetric enthapy generation rate }\left(\mathrm{kg} / \mathrm{m}^{3} / \mathrm{s}\right) \\
& f_{T}=\text { total flow resistance }(\text { form }+ \text { friction }+ \text { drag }+\ldots) \\
& \Delta P_{K, \text { source }}=\text { pressure source such as from pumps or circulators } \\
& \Delta P_{\text {extra }}=\text { other pressure gain (or loss) e.g. gravity }
\end{aligned}
$$

Discretize equation (10) and rewrite as :

$$
\frac{V_{i}}{\Delta t}\left(\rho_{i}^{n+1}-\rho_{i}^{n}\right)=\sum_{j=1}^{N_{j}} \widetilde{\rho}_{j}^{n} A_{j} u_{j}^{n+1}+S_{m, i}^{n} V_{i}
$$

Discretize equation (11) and rewrite as :

$$
\frac{V_{i}}{\Delta t} \rho_{i}^{n}\left(h_{i}^{n+1}-h_{i}^{n}\right)+\frac{V_{i}}{\Delta t} h_{i}^{n}\left(\rho_{i}^{n+1}-\rho_{i}^{n}\right)=\sum_{j=1}^{N_{j}} \widetilde{\rho}_{j}^{n} \widetilde{h}_{j}^{n} A_{j} u_{j}^{n+1}+S_{h, i}^{n} V_{i}
$$


Taylor expand $\rho$ terms of $\mathrm{P}$ and $\mathrm{h}$, and approximate to first order terms :

$\rho_{i}^{n+1}=\rho_{i}^{n}+\left(\frac{\partial \rho}{\partial h}\right)_{i}^{n}\left(h_{i}^{n+1}-h_{i}^{n}\right)+\left(\frac{\partial \rho}{\partial P}\right)_{i}^{n}\left(P_{i}^{n+1}-P_{i}^{n}\right)$

Substitute Equation (15) in Equation (13) :

$$
\begin{aligned}
& \frac{V_{i}}{\Delta t}\left[\left(\frac{\partial \rho}{\partial h}\right)_{i}^{n}\left(h_{i}^{n+1}-h_{i}^{n}\right)+\left(\frac{\partial \rho}{\partial P}\right)_{i}^{n}\left(P_{i}^{n+1}-P_{i}^{n}\right)\right]=\sum_{j=1}^{N_{j}} \widetilde{\rho}_{j}^{n} A_{j} u_{j}^{n+1}+S_{m, i}^{n} V_{i} \\
& \text { or, } \frac{V_{i}}{\Delta t}\left(\frac{\partial \rho}{\partial h}\right)_{i}^{n} \delta h_{i}^{n+1}+\frac{V_{i}}{\Delta t}\left(\frac{\partial \rho}{\partial P}\right)_{i}^{n} \delta P_{i}^{n+1}=S_{m, i}^{n} V_{i}+\sum_{j=1}^{N_{j}} \widetilde{\rho}_{j}^{n} A_{j} u_{j}^{n+1}
\end{aligned}
$$

where

$$
\begin{aligned}
& \delta h_{i}^{n+1}=h_{i}^{n+1}-h_{i}^{n} \\
& \delta P_{i}^{n+1}=P_{i}^{n+1}-P_{i}^{n}
\end{aligned}
$$

Substitute Equation (15) in Equation (14) :

$$
\begin{aligned}
& \frac{V_{i}}{\Delta t} \rho_{i}^{n} \delta h_{i}^{n+1}+\frac{V_{i}}{\Delta t} h_{i}^{n}\left(\left(\frac{\partial \rho}{\partial h}\right)_{i}^{n} \delta h_{i}^{n+1}+\left(\frac{\partial \rho}{\partial P}\right)_{i}^{n} \delta P_{i}^{n+1}\right)=S_{h, i}^{n} V_{i}+\sum_{j=1}^{N_{j}} \widetilde{\rho}_{j}^{n} \widetilde{h}_{j}^{n} A_{j} u_{j}^{n+1} \\
& \text { or, } \frac{V_{i}}{\Delta t}\left[\rho_{i}^{n}+h_{i}^{n}\left(\frac{\partial \rho}{\partial h}\right)_{i}^{n}\right] \delta h_{i}^{n+1}+\frac{V_{i}}{\Delta t} h_{i}^{n}\left(\frac{\partial \rho}{\partial P}\right)_{i}^{n} \delta P_{i}^{n+1}=S_{h, i}^{n} V_{i}+\sum_{j=1}^{N_{j}} \widetilde{\rho}_{j}^{n} \widetilde{h}_{j}^{n} A_{j} u_{j}^{n+1}
\end{aligned}
$$

Put Equation (16) and (17) in Matrix form :

$$
\left[\begin{array}{ll}
a_{11} & a_{12} \\
a_{21} & a_{22}
\end{array}\right] \bullet\left[\begin{array}{l}
\delta h_{i}^{n+1} \\
\delta P_{i}^{n+1}
\end{array}\right]=\left[\begin{array}{l}
S_{1} \\
S_{2}
\end{array}\right]+\sum_{j=1}^{N_{j}}\left\{\left[\begin{array}{l}
C_{1 j} \\
C_{2 j}
\end{array}\right] u_{j}^{n+1}\right\}
$$

where

$$
\begin{array}{ll}
a_{11}=\frac{V_{i}}{\Delta t}\left(\frac{\partial \rho}{\partial h}\right)_{i}^{n}, & a_{12}=\frac{V_{i}}{\Delta t}\left(\frac{\partial \rho}{\partial P}\right)_{i}^{n} \\
a_{21}=\frac{V_{i}}{\Delta t}\left[\rho_{i}^{n}+h_{i}^{n}\left(\frac{\partial \rho}{\partial h}\right)_{i}^{n}\right], & a_{22}=\frac{V_{i}}{\Delta t} h_{i}^{n}\left(\frac{\partial \rho}{\partial h}\right)_{i}^{n} \\
S_{1}=S_{m, i}^{n} V_{i}, & S_{2}=S_{h, i}^{n} V_{i} \\
C_{1 j}=\widetilde{\rho}_{j}^{n} A_{j}, & C_{2 j}=\widetilde{\rho}_{j}^{n} \widetilde{h}_{j}^{n} A_{j}
\end{array}
$$


Equation (18) can be re-written as

$$
[A] \bullet\left[\begin{array}{l}
\delta h_{i}^{n+1} \\
\delta P_{i}^{n+1}
\end{array}\right]=\left[\begin{array}{l}
S_{1} \\
S_{2}
\end{array}\right]+\sum_{j=1}^{N_{j}}\left\{\left[\begin{array}{l}
C_{1 j} \\
C_{2 j}
\end{array}\right] u_{j}^{n+1}\right\}
$$

Find inverse of $[\mathrm{A}]$ and multiplying both sides (see Appendix) :

$$
\begin{aligned}
& {\left[\begin{array}{l}
\delta h_{i}^{n+1} \\
\delta P_{i}^{n+1}
\end{array}\right]=[A]^{-1} \bullet\left[\begin{array}{l}
S_{1} \\
S_{2}
\end{array}\right]+\sum_{j=1}^{N_{j}}\left\{[A]^{-1} \bullet\left[\begin{array}{l}
C_{1 j} \\
C_{2 j}
\end{array}\right] u_{j}^{n+1}\right\}} \\
& \text { or, }\left[\begin{array}{l}
\delta h_{i}^{n+1} \\
\delta P_{i}^{n+1}
\end{array}\right]=\left[\begin{array}{l}
\sigma_{1} \\
\sigma_{2}
\end{array}\right]+\sum_{j=1}^{N_{j}}\left\{\left[\begin{array}{l}
\phi_{1 j} \\
\phi_{2 j}
\end{array}\right] u_{j}^{n+1}\right\}
\end{aligned}
$$

where

$$
[A]^{-1}=\left[\begin{array}{ll}
\alpha_{11} & \alpha_{12} \\
\alpha_{21} & \alpha_{22}
\end{array}\right], \quad\left[\begin{array}{l}
\sigma_{1} \\
\sigma_{2}
\end{array}\right]=[A]^{-1} \bullet\left[\begin{array}{l}
S_{1} \\
S_{2}
\end{array}\right], \quad\left[\begin{array}{l}
\phi_{1 j} \\
\phi_{2 j}
\end{array}\right]=[A]^{-1} \bullet\left[\begin{array}{l}
C_{1 j} \\
C_{2 j}
\end{array}\right]
$$

Collecting pressure terms only,

$$
\delta P_{i}^{n+1}=\sigma_{2}+\sum_{j=1}^{N_{j}}\left\{\phi_{2 j} u_{j}^{n+1}\right\}
$$

Now Equation (12) can be discretized and re-written as

$$
\begin{aligned}
u_{j}^{n+1} & =\frac{2}{f_{T, j} \widetilde{\rho}_{j}^{n} u_{j}^{n}}\left[\left(P_{f r o m, j}^{n+1}-P_{t o, j}^{n+1}\right)+\Delta P_{\text {from }, \text { source }, j}+\Delta P_{\text {extra }, j}\right] \\
& =\frac{2}{f_{T, j} \widetilde{\rho}_{j}^{n} u_{j}^{n}}\left[\left(P_{f r o m, j}^{n+1}-P_{f r o m, j}^{n}\right)-\left(P_{t o, j}^{n+1}-P_{t o, j}^{n}\right)+\left(P_{f r o m, j}^{n}-P_{t o, j}^{n}\right)+\Delta P_{\text {from }, \text { source }, j}+\Delta P_{\text {extra }, j}\right] \\
& =\eta_{j}\left(\delta P_{f r o m, j}^{n+1}-\delta P_{t o, j}^{n+1}\right)+\theta_{j}
\end{aligned}
$$

where

$$
\begin{aligned}
\eta_{j} & =\frac{2}{f_{T, j} \widetilde{\rho}_{j}^{n} u_{j}^{n}} \\
\theta_{j} & =\eta_{j} \cdot\left[\left(P_{\text {from }, j}^{n}-P_{t o, j}^{n}\right)+\Delta P_{\text {from }, \text { source }, j}+\Delta P_{\text {extra }, j}\right]
\end{aligned}
$$

Substitute Equation (21) into Equation (20) gives Pressure Equations for a node :

$$
\begin{aligned}
& \delta P_{i}^{n+1}=\sigma_{2 i}+\sum_{j=1}^{N_{j}}\left\{\phi_{2 j}\left(\eta_{j}\left(\delta P_{\text {from }, j}^{n+1}-\delta P_{t o, j}^{n+1}\right)+\theta_{j}\right)\right\} \\
& \text { or, } \delta P_{i}^{n+1}-\sum_{j=1}^{N_{j}}\left\{\phi_{2 j} \eta_{j}\left(\delta P_{\text {from }, j}^{n+1}-\delta P_{t o, j}^{n+1}\right)\right\}=\sigma_{2 i}+\sum_{j=1}^{N_{j}} \phi_{2 j} \theta_{j}
\end{aligned}
$$


Using Equation (23), setup ( $\mathrm{x}$ n) Pressure Matrix and solve for pressure.

Then, use Equation (22) to calculate new velocity as :

$$
u_{j}^{n+1}=\eta_{j}\left(\delta P_{f r o m, j}^{n+1}-\delta P_{t o, j}^{n+1}\right)+\theta_{j}
$$

With new velocity and Equation (20), calculate new enthalpy :

$$
\delta h_{i}^{n+1}=\sigma_{1}+\sum_{j=1}^{N_{j}}\left\{\phi_{1 j} u_{j}^{n+1}\right\}
$$

Now, all unknown variables have been calculated for the new time step.

Using new variables, thermal hydraulic states at the new time step can be calculated.

The time step calculations are repeated until satisfactory convergence in velocity, pressure and enthalpy are achieved. The single fluid equations will be extended to multi-specie fluid equation by considering the molar fractions and the partial pressures.

\subsection{Partial Load and Operating Constraints}

The nuclear and chemical plants will be subject to operating limits based on equipment capabilities and performance objectives. There will be limits specifically for full power and partial power steady-state operation and there will be limits for classes of transients. Initial work is to focus on steady-state design so the significance of operating limits to the development of HyPEP is described in this context. Arranging to ensure operating limits are satisfied is a design exercise where the values of controllable process variables such as pump flowrate, control rod position, and chemical reactant flowrate are back calculated to provide the desired value for controlled variables. That is, the controlled variables are indirectly manipulated through the controllable variables so as to stay within associated limits. Examples of process variables subject to operating limits are reactor outlet temperature, steam inlet temperature to the electrolyzer in the HTE process, and temperature and pressure of the sulfuric acid decomposition section of the SI process. Simulation models should provide the user with the capability to fix the value of controlled variables and in turn determine the values for the controllable variables that yield these. A necessary step is to communicate to the solver which variables are to be unknowns (controllable) and solved for and which variables are to be forcing functions or knowns (controlled). A load schedule is the map of controlled variables expressed as functions of controllable variables over all power. The capability to generate a load schedule exists in the GAS-PASS/H code and should be adopted in HyPEP code. See Section 5 for additional discussion. 


\section{MODELS}

Since HyPEP is to be used to calculate plant efficiency the quality of the prediction required determines the level of model detail that must be included. There are two prediction scenarios. The first is early in the project when scoping studies among design options may be performed; the second is later in the project when optimization of a particular design choice is performed. The quality of prediction is subject to three factors: the extent to which actual phenomena are modeled, the quality of the models, and the degree of spatial resolution. Engineering judgment will be used to determine the quality of prediction needed and to estimate the model uncertainty incurred by a particular selection from among these factors. A more rigorous approach exists but it involves man-years of effort and is suited more for final safety analysis. (Boyack 1990)

\subsection{Reactor and Power Conversion Unit}

The reactor and power conversion unit model will be assembled from a collection of models for basic components that include the reactor core, turbine, compressor, heat exchanger, pump, junction, and pipe. In developing models for each of these components one must choose from among ideal versus real gas treatment, polytropic versus isentropic process treatment, and spatially lumped versus discretized treatment of heat transfer and pressure drop. The choice among these options for scoping studies divides mainly according to the coolant involved. For helium at NGNP conditions a reasonable choice is ideal gas, polytropic process, and spatial lumping. For supercritical carbon dioxide the variation in properties with pressure and temperature is far from ideal so one must use real gas, isentropic efficiency, and spatial discretization for heat transfer. Generic characteristic curves for turbomachinery are probably acceptable.

For optimization of a particular design choice, real gas, isentropic process, and spatial discretization are preferred. In addition, for turbomachines, stage by stage calculation of characteristic curves for the actual coolant using a line code is preferred.

The first objective of the turbomachinery analysis is to determine key design parameters for the turbine and compressor that are necessary to achieve these state-of-the-art efficiencies for a particular set of process conditions. These design parameters can later be used to estimate the cost of the turbomachinery.

A good estimate of these design parameters can be obtained with simple correlations of the nondimensional parameters Specific Speed $\left(\mathrm{N}_{\mathrm{s}}\right)$ and Specific Diameter $\left(\mathrm{D}_{\mathrm{s}}\right)$. By using $\mathrm{N}_{\mathrm{s}}-\mathrm{D}_{\mathrm{s}}$ correlations (Balje, 1981) along with the process conditions and shaft speed for a particular plant power cycle, it is possible to determine the number of stages, stage diameters, and stage blade heights that are necessary to achieve the desired turbine and compressor efficiencies. 


$$
\begin{aligned}
\mathrm{N}_{\mathrm{s}} & =\frac{\mathrm{N} \cdot \dot{\mathrm{V}}^{.5}}{\mathrm{H}^{.75}} \quad \mathrm{D}_{\mathrm{s}}=\frac{\mathrm{D} \cdot \mathrm{H}^{.25}}{\dot{\mathrm{V}}^{.5}} \\
\mathrm{~N} & =\text { shaft speed } \\
\dot{\mathrm{V}} & =\text { actual volume flow rate }
\end{aligned}
$$

(Measured at the stage inlet for compressors and

the stage exit for turbines)

$\mathrm{H}=$ isentropic enthalpy change

$\mathrm{D}=$ blade tip diameter

The number of stages of turbine and compressors that will be included in the HYSYS model will be calculated and will be compared with those of the turbines and compressors used in the following reference systems: PBMR, GT-MHR, and GT-MHR, for example.

It should also be noted that there are several different types of turbine and compressor efficiencies that are commonly discussed in the literature. In order to avoid confusion, it is important to be aware of the type of efficiency that is being discussed. The efficiencies used in these calculations are overall isentropic efficiencies. The efficiencies that are discussed in other sections of this report are polytropic or small-stage efficiencies. For pressure ratios currently under consideration, and overall compressor efficiency of $86 \%$ corresponds to a polytropic efficiency of about $90 \%$. Furthermore, efficiencies in this report are total-to-static efficiencies between the total inlet state and the static exit state (as opposed to total-to-total efficiencies). By using total-to-static efficiencies, turbine and compressor exit losses are accounted for. Reference of Balje 1981 can be consulted for a detailed discussion of the different types of turbomachinery efficiencies.

\subsection{Thermochemical}

The sulfur-iodine water splitting cycle is a promising candidate for thermochemical hydrogen production. It consists of three chemical reactions that sum to the dissociation of water:

1. $\mathrm{H}_{2} \mathrm{SO}_{4} \rightarrow \mathrm{SO}_{2}+\mathrm{H} 2 \mathrm{O}+1 / 2 \mathrm{O}_{2}$

2. $\mathrm{xI}_{2}+\mathrm{SO}_{2}+2 \mathrm{H}_{2} \mathrm{O} \rightarrow 2 \mathrm{HI}_{\mathrm{x}}+\mathrm{H}_{2} \mathrm{SO}_{4}$

3. $2 \mathrm{HI}_{\mathrm{x}} \rightarrow \mathrm{xI}_{2}+\mathrm{H}_{2}$

The S-I process cycle is divided into three sections as depicted in Figure 7. 


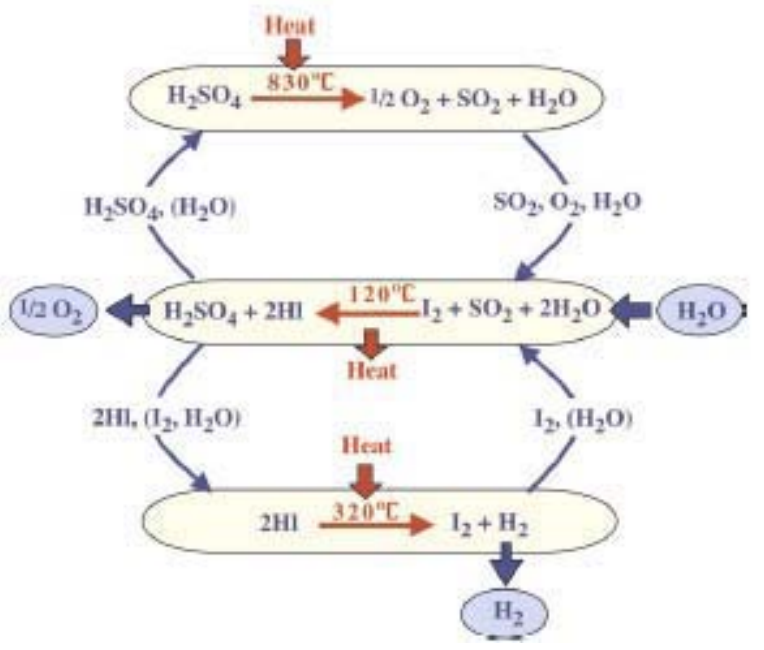

Figure 7. Three reactions in SI process.

A model will be developed for the sulfur iodine (SI) cycle identified in Section 2 as the reference thermochemical cycle for this project. The SI cycle is under development in the US, France, and Japan with recent work aimed at obtaining experiment data for improving the prediction of the equilibrium state of the reactions and at constructing laboratory-scale equipment for selecting among process options and demonstrating the integrated cycle on a laboratory-scale (Pickard, 2005). The most recent detailed description of the integrated cycle including process flowsheets is given in Brown from June 2003. It appears that the work reported in Brown (2003) is continuing under a NERI project with collaboration between General Atomics and Savannah River. That project is to issue a report in April 2006 with a more complete process flowsheet (Brown, 2005).

The current development status of the SI cycle is a factor that must be considered in deciding on an approach to model development. At this time the reference process design has not been finalized with experiments underway to aid in selecting among process options. (Pickard 2005) These options include use of reactive versus extractive distillation for the separation of iodine from the reactants and products in the $\mathrm{HI}$ decomposition section, the use of high pressure, a catalyst, and a membrane in the $\mathrm{H}_{2} \mathrm{SO}_{4}$ decomposition section, and the use of a counter-current versus co-current reactor in the Bunsen section (Brown, 2005).

The phenomena in the SI cycle and whether an integral representation of them or a detailed representation of the individual separate effects is best suited must be examined in light of project objectives. Both the $\mathrm{H}_{2} \mathrm{SO}_{4}$ decomposition section and $\mathrm{HI}$ decomposition section reactions are carried out in a network of components that involve the phenomena of flash evaporation, vapor recompression, multiple species chemical reactions, heat recuperation, reactant separation and recycle, radiative heat transfer, and two-phase heat transfer. The observation is made that to the first order the thermal behavior of the chemical process as seen at the interface is largely accounted for by the enthalpy change across each of the two sections and three lumped heat capacities that represent the structural and chemical inventories in each of the three sections in the SI cycle. A schematic is shown in Figure A-1 of the Appendix. These integral representations need not break out the separate effects listed above. From the standpoint of modeling chemical plant behavior as seen at the interface, if the integral representation in Figure A-1 can be obtained, then for scoping studies this model should be adequate. The Appendix describes what such an integrated model might look like. Essentially, each of the three SI sections is represented as a lumped parameter energy node with energy exchange between the different sections represented by mass and energy flowpaths between the nodes. A final observation is that the separate 
effects phenomena listed above are quite complex and that process modeling from separate effects standpoint might be best left to specialists and their computer codes such as Aspen Plus.

The extent to which existing flowsheet models are supported by reliable process data is a factor in the selection of an initial modeling approach. In (Brown 2003) an absence of experiment-based equilibrium or thermodynamic data above $250 \mathrm{C}$ for the sulfuric acid decomposition step required that process values be estimated at the $850 \mathrm{C}$ operating temperature. The measurement of heat transfer data for the two-phase multi-species reactions present in the high temperature section are only just getting underway (Sherman, 2005). The role and behavior of a catalyst has yet to be fully characterized. Further, an active research program for the development of a suitable heat exchanger is underway (Sherman 2005) and so channel geometry which affects heat transfer and pressure is subject to change. It also appears reaction kinetic data is not well known. Thus, in light of current research and experiments to better characterize process models, the current process flowsheet is judged preliminary and its predictive capabilities uncertain. Given this, it appears at this time that our modeling efforts should remain sufficiently high level that they avoid explicit modeling of these phenomena.

The preceding factors were considered in selecting an initial modeling approach. The main goal is to develop a capability that represents the heat load placed by the chemical plant on the interface. Given the current state of knowledge about SI process data and process options, incorporating explicit models for phenomena in existing process flowsheets seems inappropriate. The level of detail would exceed what is needed to represent heat load and heat capacity of the chemical plant as seen at the interface. Further, it would not be productive to include a level of modeling detail that implies design choices that have not yet been made at the NHI program level. The preferred approach is to represent each of the three sections as lumped regions of mass and energy that are connected through mass and energy streams. An outline of such a model is given in the Appendix. This model is calibrated using integral data obtained from an Aspen flowsheet. The model will be recalibrated as new process experiments are preformed and the Aspen flowsheet is updated to reflect the new data. Until such time as kinetics data are known, it would be premature to include models for temperature and species concentration dependent feedbacks that control the rates of chemical reactions in each section. In place of these the user provides the fractional power in each of the sections as a function of time where it is then assumed that the energy and mass flowrates leaving the section for other sections scale with this. The model is useful then for studying the temperatures and heat loads that the interface heat transfer equipment must be designed for in the steady state as implied by the detailed chemical flowsheet. It is also useful for studying the dynamic behavior of the material inventories to ensure adequate buffering of temperatures between the chemical plant and the nuclear plant to temporary imbalances in power, either in the nuclear plant or one of the sections in the SI process. Such imbalances might result from control system or component failures or human error.

The integrated model will be developed as shown in Figure 3 that includes the reactor, PCU, IHTC and S-I process.

\subsection{High Temperature Electrolysis}

A schematic of a nuclear hydrogen plant using HTE is shown in Figure 8. The VHTR supplies thermal energy to drive the PCU and to heat steam for the electrolysis process. The high temperature heat exchanger supplies superheated steam to the cells at a temperature of approximate $850 \mathrm{C}$ and a pressure of $5 \mathrm{MPa}(725 \mathrm{psi})$. The input gas contains both steam and hydrogen in order to maintain reducing conditions at the electrolyte conditions. 


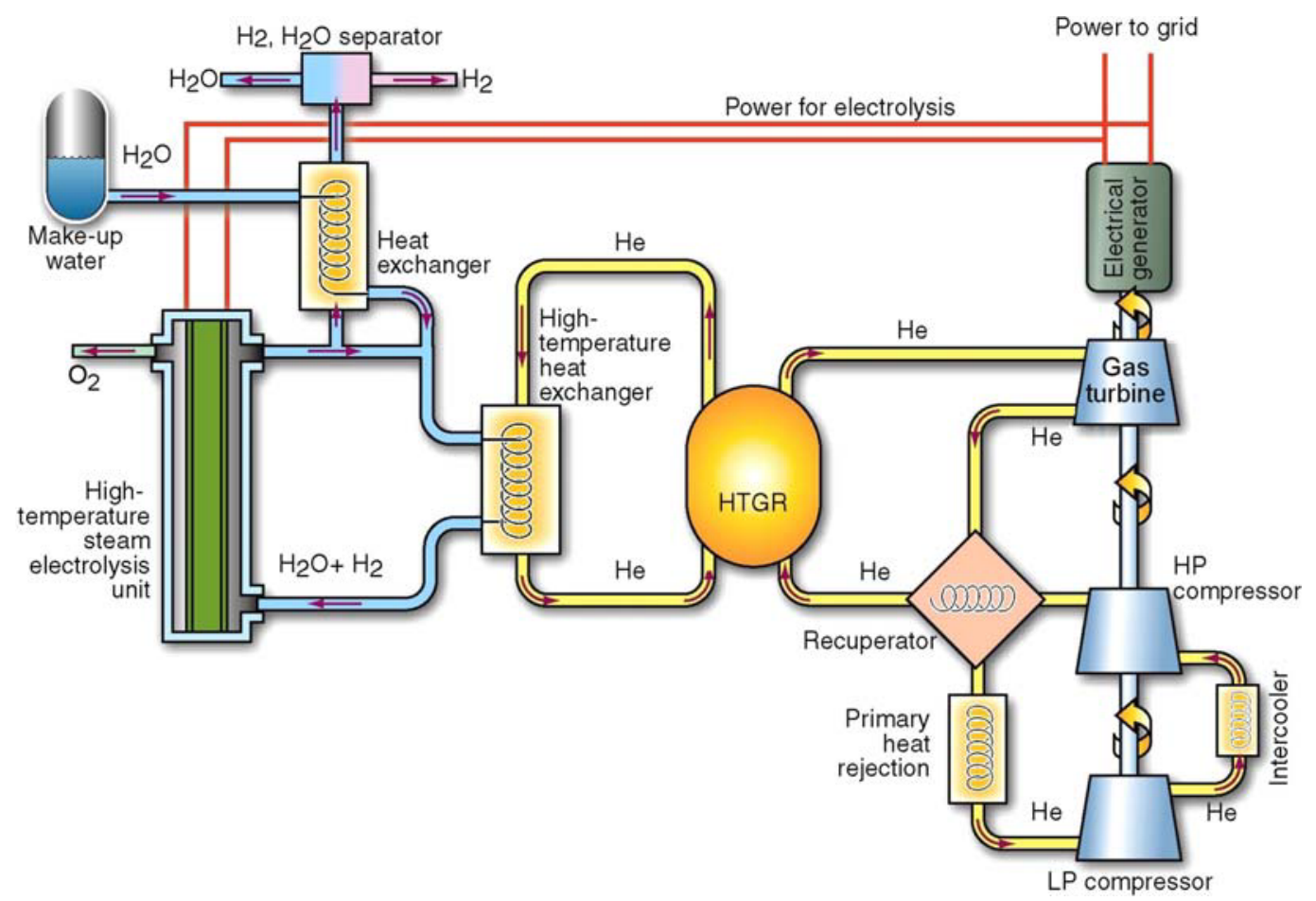

Figure 8. THE system coupled with VHTR.

A model will be developed for the high temperature electrolysis (HTE) process identified in Section 2 as the reference electrochemical cycle for this project. This cycle is under development in the US with recent work aimed at developing energy-efficient, high temperature, solid-oxide electrolysis cells (SOEC) (Herring, 2005). Presently, tests are being performed on stacks of SOECs operating in the electrolysis mode and plans are to perform integrated laboratory-scale experiments. The most recent detailed description of the integrated cycle including process flowsheets is given in Stoots (2005). That report describes a configuration of heat exchangers, pumps, compressors, turbines, and electrolytic cells that use reactor plant process heat and electricity to electrolyze steam at high temperature. The performance dependence on engineering parameter values is explored and the use of different sweep gases is examined.

The HTE process is simpler than the SI cycle from the standpoint of phenomena and flowsheet complexity. In place of multiple nonlinear chemical equilibria there is a single chemical reaction involving water and a solid-state electrolyte. While the electrode chemistry may be complex the integral behavior is relatively simple. It can be represented in terms of cell electrical resistance and Nernst potential which are readily measured and modeled. A HYSYS steady-state model for the integrated HTE cycle has been developed at INL (Stoots 2005). This model appears to be a reasonable one for representing the hydrogen production side of the interface and adopting it for HyPEP would avoid duplication of effort.

In the longer term dynamic models are needed to study certain issues that arise when the HTE process is interfaced to the nuclear plant. One requirement is for strict control of temperature rate of change in the SOECs to limit thermally-induced mechanical stress. The stability of the coupled nuclear and chemical plants will be a factor in how well temperatures can be regulated during load changes or upsets. Some insight into the type of model needed is obtained by examining the phenomena that give rise to dynamic behavior. Mass and energy storage giving rise to large time constants coupled with energy production that is temperature or pressure dependent can potentially create oscillatory behavior. Within 
the HTE process a significant source for mass and energy storage is the subcooled water that undergoes a phase change upstream of the electrolytic cell. Process heat loops from the reactor to the hydrogen plant will have large time constants. Combined with electrolysis where the rate of electrical energy consumption has a pressure and temperature dependence there is the potential for oscillatory behavior. A model capable of predicting such behavior would need these phenomena represented. A simplified version of the INL process flowsheet (Stoots 2205) that includes these phenomena is shown in Figure 9. It is proposed that a model for this flowsheet be developed. It could be used to investigate control strategies that seek to moderate electrolytic cell temperature using the two phase water inventory as a buffer to absorb temperature changes caused by temporary imbalances in energy production and consumption. It could also be used to investigate the potential for oscillatory behavior that might follow from this.

Figure 4 in Section 2 depicts the simplified HTE model that will be used in FY-06 task.

\subsection{Thermophysical Properties}

\section{Liquid salts}

Liquid salts are being considered as the working fluid in the intermediate heat transport loop (Davis et al., 2005). The salts considered were LiF-NaF-KF (Flinak) in molar concentrations of 46.5\%, 11.5\%, and $42 \%$, respectively, and $\mathrm{NaBF}_{4}-\mathrm{NaF}$ in molar concentrations of $92 \%$ and $8 \%$. $\mathrm{NaBF}_{4}-\mathrm{NaF}$ is considered to be a better candidate for the intermediate heat transport loop because of its lower melting point $\left(385\right.$ vs. $\left.454^{\circ} \mathrm{C}\right)$. Thermodynamic and transport properties for these salts are described by Davis (2005). The correlations given by Davis (2005) should be acceptable to use for implementing liquid salt properties in HyPEP.

\section{Process fluids}

The hydrogen production process utilizes three separate fluid systems: $\mathrm{H}_{2} \mathrm{SO}_{4}-\mathrm{H}_{2} \mathrm{O}, \mathrm{HI}-\mathrm{I}_{2}-\mathrm{H}_{2} \mathrm{O}$, and $\mathrm{H}_{2} \mathrm{SO}_{4}-\mathrm{HI}_{\mathrm{x}}-\mathrm{H}_{2} \mathrm{O}$ (Brown et al. 2003). Thus, the primary fluids of interest are $\mathrm{H}_{2} \mathrm{SO}_{4}, \mathrm{H}_{2} \mathrm{O}, \mathrm{HI}$, and $\mathrm{I}_{2}$. Both liquid and vapor phases of each of the primary fluids exist at some point in the process. Thermodynamic data are generally available for the pure fluids, although not necessarily at the temperatures and pressures needed for the hydrogen production process. For example, Perry and Green (1997) present thermodynamic data for $\mathrm{H}_{2} \mathrm{SO}_{4}$ at temperatures up to $350{ }^{\circ} \mathrm{C}$. However, the temperature of $\mathrm{H}_{2} \mathrm{SO}_{4}$ in the proposed hydrogen production process exceeds $800^{\circ} \mathrm{C}$. Furthermore, the thermodynamic properties of liquid mixtures do not depend solely on the properties of the pure components and their respective molar concentrations. Consequently, the thermodynamic properties must be determined by measurement for each separate fluid system. Because of the lack of experimental data, Brown et al. (2003) developed empirical models that fit the existing low-temperature data and applied the models to predict properties at the proposed conditions for hydrogen production. Brown et al. concluded that the model for the $\mathrm{H}_{2} \mathrm{SO}_{4}-\mathrm{H}_{2} \mathrm{O}$ system would provide a reliable description for Section 2 of the Sulfur-Iodine cycle. The model for the $\mathrm{HI}-\mathrm{I}_{2}-\mathrm{H}_{2} \mathrm{O}$ system was expected to provide reasonable predictions of Section 3 , but experimental data were needed for validation. The results from the model of the $\mathrm{H}_{2} \mathrm{SO}_{4}-\mathrm{HI}_{\mathrm{x}}-\mathrm{H}_{2} \mathrm{O}$ system were judged to require caution because of the small range of the underlying data. 


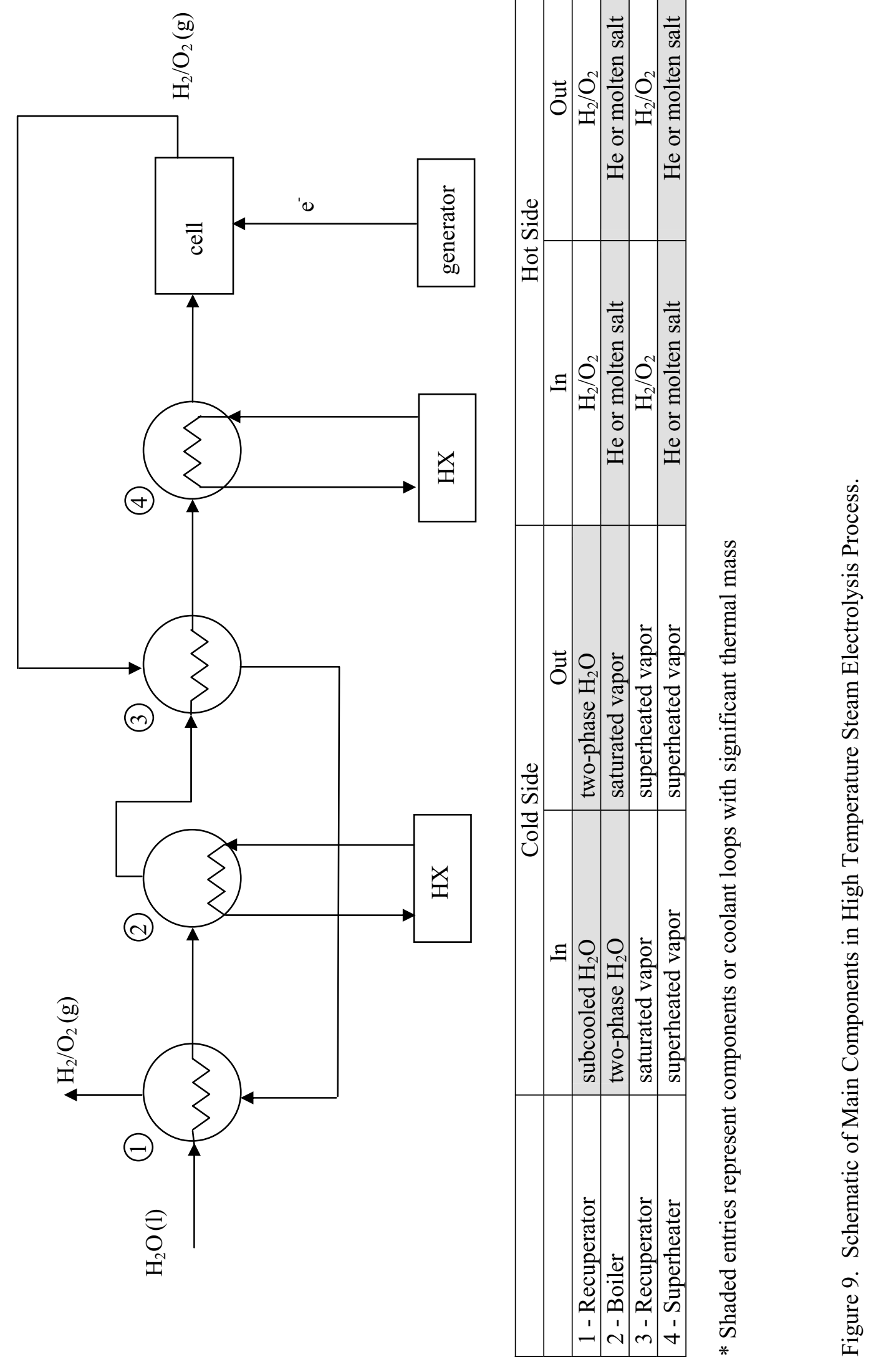


At the current time, the existing models of Brown et al. (2003) are expected to provide the best estimates of thermodynamic properties. These flowsheet models could be obtained from General Atomics to provide thermodynamic properties for use in HyPEP. However, better properties might be obtained from General Atomic's improved thermodynamic models that should be available early in 2006. The French are also expected to report basic thermodynamic data at conditions more applicable to the hydrogen production process in 2006 . Improved models could also be generated using the French data and the regression feature of Aspen Plus.

The transport properties of dynamic viscosity and thermal conductivity are also available for the pure fluids required in the hydrogen production process. For example, Daubert et al. (2000) present correlations for both liquid and vapor phases of $\mathrm{H}_{2} \mathrm{SO}_{4}, \mathrm{H}_{2} \mathrm{O}, \mathrm{HI}$, and $\mathrm{I}_{2}$. As was the case for the thermodynamic properties, the combination of properties of the pure fluids to determine mixture properties is more difficult. According to Govier and Aziz (1972), the viscosity of a miscible liquid mixture cannot be predicted reliably. Thus, they recommend an approximate method, such as linear weighting of the viscosities of the pure components based on the mass fraction. A similar method could be used for the thermal conductivity. For mixtures of gases, the Wilke formula described by Bird et al. (1960) should be sufficiently accurate.

When the gas must be treated as real the NIST database (NIST Reference 7.0) will be used. The evaluation of properties in NIST, however, can be numerically intensive and result in long execution times which would not be in keeping with HyPEP objectives, i.e. to rapidly prototype different design options. In this case a tabular approach to property evaluation can be used to speed execution (Hejzlar).

\subsection{Cost Analysis Model}

In this task, models for overnight capital cost and component cost are to be developed. As the determination of the "true cost" of a nuclear plant requires consideration of a large number of empirical and difficult-to-establish factors, the models to be developed will be very simple models. The developed models will essentially provide rough guidance on the economics of various plant layouts.

The cost analysis model will involve collection and categorization of cost models for various major components and systems. With the component cost models incorporated, the cost model for HyPEP will be further developed to estimate the overnight cost of the system.

An optimization model will also be developed. A scheme will be provided by which the optimization can be performed by a large number of calculations by varying the parameters of interest. A batch style calculation scheme is deemed to be best-suited for the optimization calculations, and an automatic way to carry out the calculation will be pursued in this task. 


\section{COMPUTATIONAL STRATEGIES}

The computational strategy for the HyPEP code is being developed by KAERI under an I-NERI agreement. The agreement is to develop the steady state solution scheme for the coupled nuclear and chemical plant (Oh, 2005). Separately, in the U.S. there is interest outside of the I-NERI agreement in the laying groundwork for a transient code capability. The GAS-PASS/H code (Vilim, 2004) is one potential starting point. The code parallels HyPEP in capabilities in that it is a module-based network systems code. Both codes allow reactor configurations to be assembled from existing plant component modules without having to reprogram source code. A brief description of the computational scheme in GAS$\mathrm{PASS} / \mathrm{H}$ provides perspective on how new models for the nuclear and chemical plant components can be interfaced to the code.

\subsection{Assembler}

Any plant component model that can be written as a set of ordinary differential equations (dynamic case) or algebraic equations (quasi-static case) can be interfaced to the GAS-PASS/H code. The equations are first order time differenced and entered as a set of equations of the form $0=f\left(x^{i+1}, x^{i}, u^{i}\right)$ where $x^{i+1}$ is a vector of the variables to be solved for at the new time, $x^{i}$ are the values at the old time, and $u^{i}$ is a vector of forcing functions held constant between time $i$ and $i+1$. The equations for a component are entered in a subroutine module set aside for that component. The network diagram the user assembles as part of the code input stream describes the inter-connections among plant components and is used by the code to link modules to the numerical scheme. The user input also specifies which variables are to be treated as unknowns to be solved for and which are to be treated as forcing functions.

\subsection{Solver}

The numerical solver is normally transparent to the user. However, there are several conditions that must be satisfied before a reliable solution is returned. First, all model variables that are either to be solved for or are forcing function variables must be marked as such in the input. Second, for the complete system the total number of unknowns solved for must equal the number of equations. Thus, when a user adds a new model, he must maintain this balance when identifying which variables are unknowns and which are forcing functions. 


\section{VERIFICATION AND VALIDATION}

In order to verify and validate the numerical tools, the following design case will be used for $\mathrm{V} \& \mathrm{~V}$ purpose. One candidate for the V\&V is the GTHTR-300 design (Yan et al., 2003), that is a direct-cycle gas cooled reactor that uses a distributed power conversion system with horizontal turbomachinery and heat exchangers located in separate vessels, as shown in Figure 10.

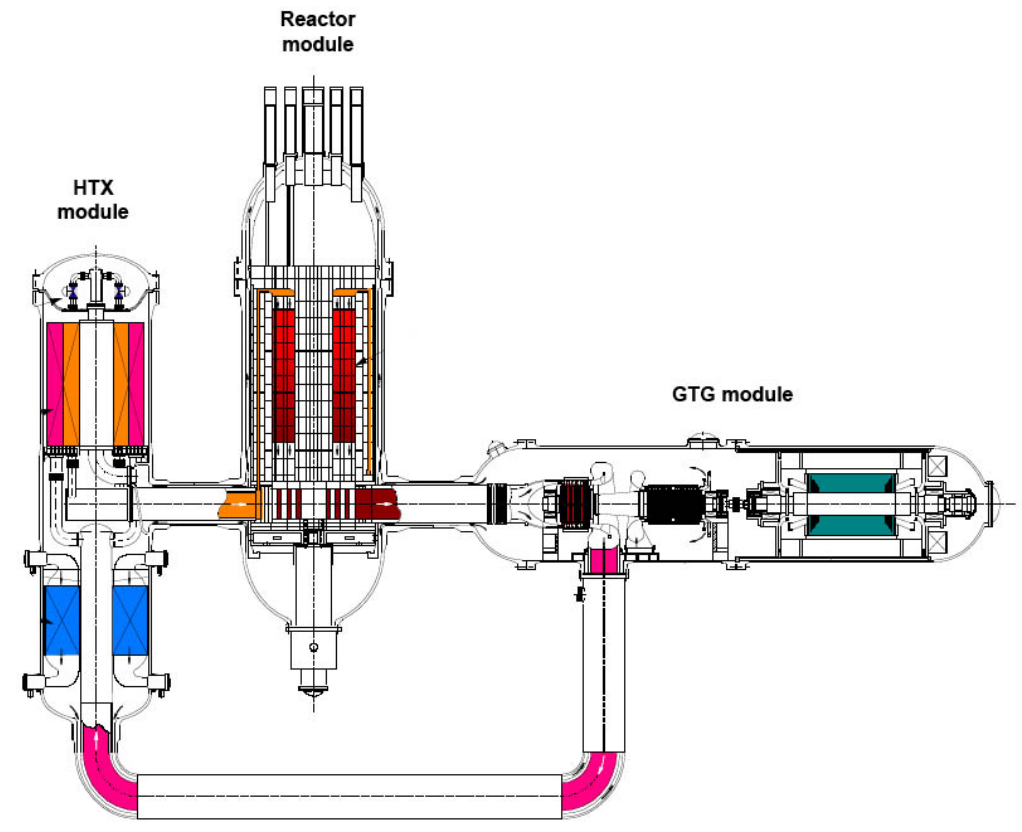

Figure 10. GTHTR-300 reactor and power conversion system.

Figure 11 shows the schematic of GTHTR-300 reactor and Figure 12 shows cycle efficiency calculated a design value and a range of parameters varied.

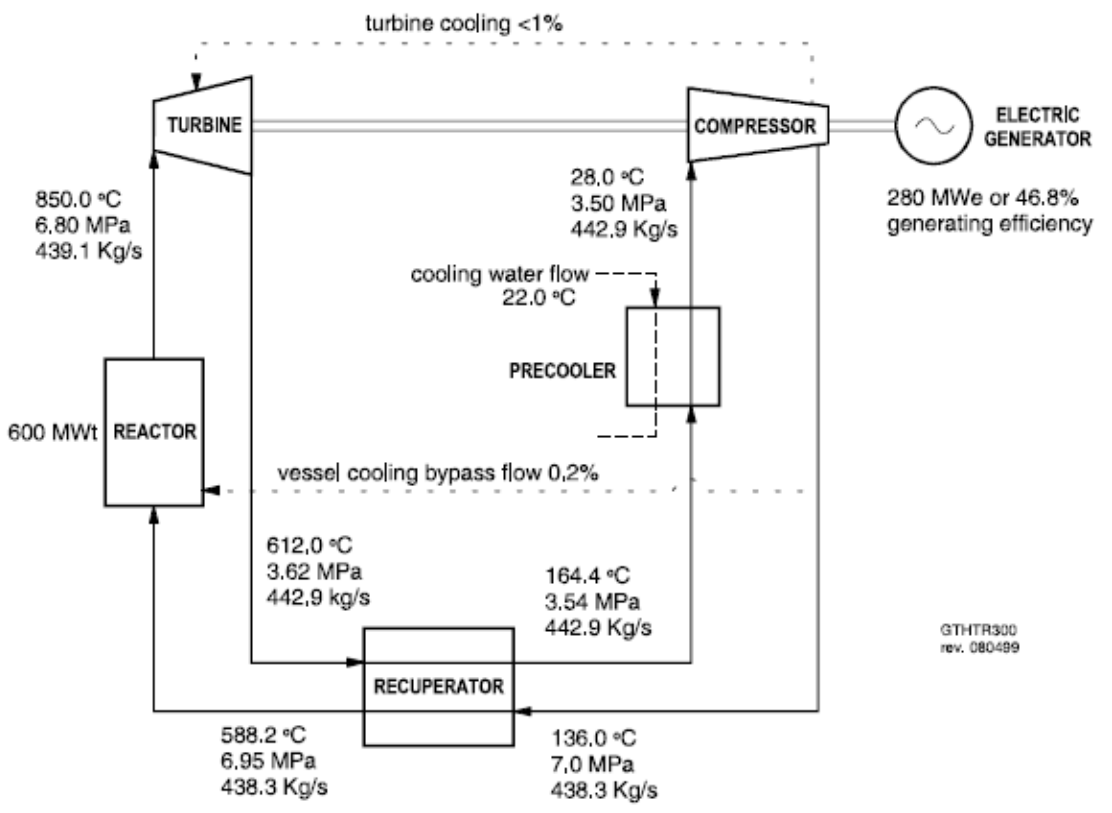

Figure 11. Schematic of GTHTR-300 design. 


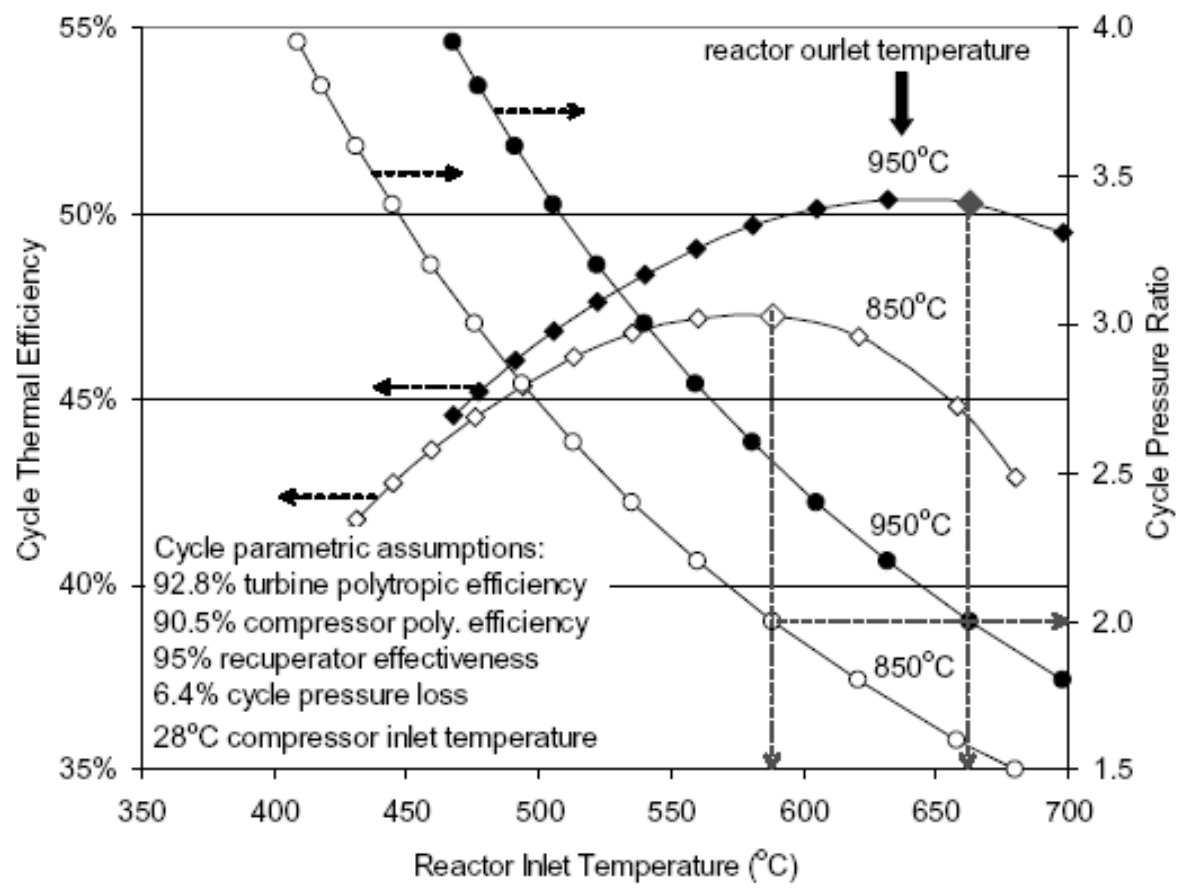

Figure 12. Cycle efficiency as a function of reactor inlet temperature.

In addition to $\mathrm{V} \& \mathrm{~V}$ describe above, the discharge temperature from the expander and compressor from the code calculations will be compared with the $\mathrm{P}-\mathrm{H}$ diagram described in section 3.2 (Figures 5 and 6). 


\section{SYSTEM INTEGRATION}

This section consists of two parts: Process integration and control strategy for PCU and $\mathrm{H}_{2}$ plant.

\subsection{Process Integration}

This task includes the integration of the VHTR, PCU, and hydrogen plant through the intermediate heat transfer loop (IHTC). FY-06 task involves the identification of the major system, components, and operating conditions of reactor, PCU, IHTC, and hydrogen plant. As shown in Figures 3 and 4 in the section of the reference design (Section 2), simplified and representative blocks of thermochemical S-I process and THE will be modeled. For these calculations, typical mass and energy balance around the simplified component blocks in S-I and THE process are used. FY-07 task involves the optimization of PCU configuration and parametric investigation, and comparison of results from HyPEP,HYSYS, and Gass/PASS. FY-08 task involves size calculations of the major components in the entire system and the complete system integration.

\subsection{Control Strategy for PCU and $\mathrm{H}_{2}$ Plant}

Engineering data for the reference design of the nuclear plant and the chemical plant will be compiled. Engineering data will also be compiled for the heat transfer interface between the nuclear and chemical plants. These data are needed for setting up a steady-state model of the coupled plant.

A list of equipment operating limits for the nuclear plant and the chemical plant will be compiled. The interface must function so that these limits are not exceeded. The product mix to the distribution system, i.e. hydrogen and electricity will be specified. This may include the ability to vary the mix in a quasi-static manner. The interface must be designed to provide for this.

A major task is to determine how the product mix can be met without exceeding the limits on plant equipment. Control strategies for achieving this will be identified. This requires selecting the appropriate actuators and specifying how they are coordinated. Actuators on the nuclear side include pumps in coolant loops, control rods, turbine bypass valve, electric generator frequency, and primary system gas inventory charging valve. In the chemical plant, for the SI process there are the power levels of the individual sections and the associated feed rates of reactants as described in the Appendix. For the HTE process there is the power to the electrolyzer, the water feedstock flowrate, and the low and high temperature heat inputs from the reactor which are functions of flowrates in the interface coolant circuits.

A GAS-PASS model will be developed to evaluate control strategy performance. The model for the chemical plant will be based on the description given in Sections 4.2 and 4.3. Whether work will focus on the SI, the HTE cycle, or both will be the subject of discussions among project participants.

The steady-state load performance of the coupled plant as measured by how well process variables are maintained within limits while providing the product mix will be investigated. This will involve simulating plant response during changes in the boundary conditions that represent the demands placed by the distribution system on the plant. Energy storage terms will be set to zero so only the plant quasi-static behavior is observed. The goal is to identify the control system requirements such that process variable limits are met for changes in distribution system demand.

In FY2007 work will continue on control strategy development for the steady state while work will begin on transient analyses of the plant for study of operational control issues including startup and shutdown and upsets in the hydrogen plant and the nuclear plant. Key to this is a basic knowledge of the 
important system time constants and an understanding of the phenomena that control plant stability. We will characterize these. This will provide insight into how passive feedback mechanisms can be used to increase stability (i.e., damping time response) and how passive energy storage (e.g., equipment heat capacity) can be used to mitigate transient imbalances in energy generation and consumption that otherwise lead to transient overshoots in process variables. These imbalances can arise as a result of the plant having limited product storage capability yet still having to meet time-varying demands from the distribution system for product.

In FY2008 the control system design will be completed. 


\section{PROJECT SCHEDULE AND MILESTONE}

\begin{tabular}{|c|c|c|c|}
\hline Year & $\mathrm{Lab}$ & Milestone/Deliverable Description & $\begin{array}{l}\text { Planned } \\
\text { Completion }\end{array}$ \\
\hline \multirow[t]{8}{*}{$2005-2006$} & KAERI & $\begin{array}{l}\text { Report describing the modeling basis, extent and the } \\
\text { capability of HyPEP. }\end{array}$ & $8 / 31 / 06$ \\
\hline & INL & Requirements and assumptions & $8 / 31 / 06$ \\
\hline & & $\begin{array}{l}\text { Identify major systems, components, and operating } \\
\text { parameters of PCU and hydrogen plant }\end{array}$ & \\
\hline & & Identify program qualification methodology & \\
\hline & & and development of PCU configurations & \\
\hline & ANL & Development of database of engineering data & $8 / 31 / 06$ \\
\hline & & $\begin{array}{l}\text { Including equipment operating limit for PCU and } \\
\text { hydrogen plants }\end{array}$ & \\
\hline & & $\begin{array}{l}\text { Simulation and analysis of steady-state behavior and } \\
\text { quasi-static partial operation }\end{array}$ & \\
\hline \multirow[t]{6}{*}{2007} & KAERI & $\begin{array}{l}\text { Interim report describing the models and correlations of } \\
\text { HyPEP. }\end{array}$ & $8 / 31 / 07$ \\
\hline & INL & Optimization with PCU configurations & $8 / 31 / 07$ \\
\hline & & Parametric studies with various working fluids & \\
\hline & & $\begin{array}{l}\text { Study of design options such as pressure, temperature, } \\
\text { etc. }\end{array}$ & \\
\hline & ANL & Development of control strategy & $8 / 31 / 07$ \\
\hline & & $\begin{array}{l}\text { Transient analyses for plant upsets, control strategy, etc } \\
\text { for hydrogen plants and PCU. }\end{array}$ & \\
\hline \multirow[t]{10}{*}{2008} & KAERI & HyPEP Models and Correlation Report & $4 / 31 / 08$ \\
\hline & & HyPEP User's Manual & $8 / 31 / 08$ \\
\hline & INL & $\begin{array}{l}\text { Heat exchanger performance and turbine compressor } \\
\text { stage calculations. }\end{array}$ & $8 / 31 / 08$ \\
\hline & & System integration of models and software & \\
\hline & & $\begin{array}{l}\text { Work with ANL to incorporate separate models into } \\
\text { whole and help perform model testing and qualification }\end{array}$ & \\
\hline & & Final report & \\
\hline & ANL & Completion of control system & $8 / 31 / 08$ \\
\hline & & Study of Competing Designs & \\
\hline & & $\begin{array}{l}\text { Work with INL to incorporate separate models into } \\
\text { whole and help perform model testing and qualification }\end{array}$ & \\
\hline & & Final report to INL & \\
\hline
\end{tabular}

The project schedule for KAERI is illustrated in the chart below. Brief annual progress reports will be issued at the end of Year 1 and Year 2, to summarize the technical progresses. These reports will be submitted to MOST. A final report will be issued at the end of Year 3 that will exhaustively describe the project results. 


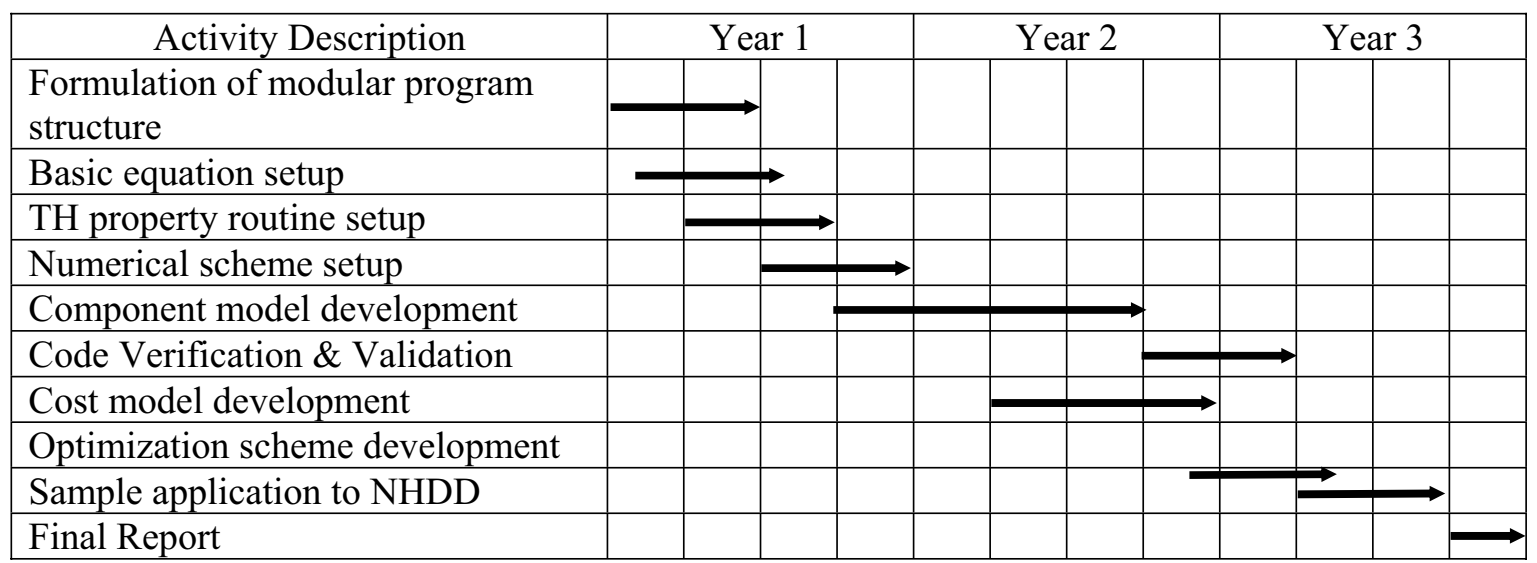




\section{REFERENCES}

Bird, R. B., W. E. Stewart, and E. N. Lightfoot, Transport Phenomena, John Wiley \& Sons, Inc., New York, 1960.

Brown, L. C., G. E. Besenbruch, R. D. Lentsch, K. R. Schultz, J. F. Funk, P. S. Pickard, A. C. Marshall, and S. K. Showalter, High Efficiency Generation of Hydrogen Fuels Using Nuclear Power, Final Technical Report for the Period August 1, 1999 through September, 30, 2002, GA-A24285, June 2003.

Brown, L., "Sulfur-Iodine Flowsheets," UNLV Research Foundation HTHX

Quarterly Meeting, University of Nevada - Las Vegas, December 5, 2005.

Brown, L., General Atomics, personal communication, December 2005.

Brown, L. et. al, "High Efficiency Generation of Hydrogen Fuels Using Nuclear

Power," GA-A24285, June 2003.

Boyack, B. E., et al., "An Overview of Code Scaling, Applicability, and Uncertainty Methodology," Nuclear Engineering and Design 119 (1990), pp. 1-15.

Daubert, T. E. et al., Physical and Thermodynamic Properties of Pure Chemicals Evaluated Process Design Data, American Institute of Chemical Engineers and Design Institute for Physical Property Data, 2000.

Davis, C. B., Implementation of Molten Salt Properties into RELAP5-3D/ATHENA, INEEL/EXT-0502658, January, 2005.

Davis, C. B., C. H. Oh, R. B. Barner, S. R. Sherman, and D. F. Wilson, Thermal-Hydraulic Analyses of Heat Transfer Fluid Requirements and Characteristics for Coupling a Hydrogen Production to a High-Temperature Nuclear Reactor, INL/EXT-05-00453, June 2005.

Dostal, V., M. J. Driscoll, and P. Hejzlar, A Supercritical Carbon Dioxide Cycle for Next Generation Nuclear Reactors, MIT-ANP-TR-100, March 10, 2004.

General Atomics, 1996, Gas Turbine-Modular Helium Reactor (GT-MHR) Conceptual Design Description Report, GA Project No. 7658, 910720 Revision 1, July 1996.

Govier, G. W. and K. Aziz, The Flow of Complex Mixtures in Pipes, Van Nostrand Reinhold Company, New York, 1972.

Balje, O. E., Turbomachines, A Guide to Design, Selection, and Theory, John Wiley and Sons, Inc., 1981.

Hejzlar, Pavel, personal communication, Massachusetts Institute of Technology, 2005.

Independent Technology Review Group, Design Features and Technology Uncertainties for the Next Generation Nuclear Plant, INEEL/EXT-04-01816, June 30, 2004.

Ishizuka, T., Y. Kato, Y. Muto, K. Nikitin, N. L. Tri, and H. Hashimoto, "Thermal-Hydraulic Characteristics of a Printed Circuit Heat Exchanger in a Supercritical $\mathrm{CO}_{2}$ Loop," The $11^{\text {th }}$ International Topical Meeting on Nuclear Reactor Thermal-Hydraulics (NURETH-11), Avignon, France, October 2-6, 2005.

Lillo, T. M., R. L. Williamson, T. R. Reed, C. B. Davis, and D. M. Ginosar, Engineering Analysis of Intermediate Loop and Process Heat Exchanger Requirements to Include Configuration Analysis and Materials Needs, INL-EXT-05-00690, September, 2005. 
MacDonald, P. E., J. W. Sterbentz, R. L. Sant, P. D. Bayless, R. R. Schultz, H. D. Gougar, R. L. Moore, A. M. Ougouag, and W. K. Terry, 2003, NGNP Preliminary Point Design-Results of the Initial Neutronics and Thermal-Hydraulic Assessments, INEEL/EXT-03-00870, July 2003.

NIST Reference Fluid Thermodynamic and TransportPropertiesDatabase(REFPROP):Version 7.0

Perry, R. H. and D. W. Green, Perry's Chemical Engineers' Handbook, Seventh Edition, McGraw-Hill, 1997.

Pickard, P.S. "Sulfur-Iodine Thermochemical Cycle," FY2005 Progress Report, DOE Hydrogen Program, www.hydrogen.energy.gov/pdfs/progress05, 2005.

Sherman, S., "NHI System Interface and Support Systems," 2005 DOE Hydrogen Program, Idaho National Laboratory, May 25, 2005.

Herring, S., "High Temperature Electrolysis," FY2005 Progress Report, DOE Hydrogen Program, www.hydrogen.energy.gov/pdfs/progress05, 2005

Oh, C.H., C.B. Davis, S.R. Sherman, and R. Vilim, "Development of HyPEP, A Hydrogen Production Plant Efficiency Calculation Program,” U.S./Republic of Korea I-NERI agreement, 2005.

Sochet, I., J. L. Rouyer, and P. Hemmerich, 2004, "Safe Hydrogen Generation by Nuclear HTR," Paper 4261, Proceedings of ICAPP '04, Pittsburgh, PA, USA, June 13-17.

Smith, C., S. Beck, and B. Galyean, 2005, An Engineering Analysis for Separation Requirements of a Hydrogen Production Plant and High-Temperature Nuclear Reactor, INL/EXT-05-00137 Rev 0, March 2005.

Stoots, C.M., "Engineering Process Model for High-Temperature Electrolysis System Performance Evaluation," Idaho National Laboratory, 2005.

Vernondern, K. and T. Nishihara, 2004, Valuation of the Safety Concept of the Combined Nuclear/Chemical Complex for Hydrogen Production with HTTR, JUEL-4135.

Vilim, R.B., U. Mertyurek, and J. Cahalan, "Passive Safety Analysis of the Gas Fast ReactorUsing the GAS-PASS/H Systems Code,” ICAPP 2004, Pittsburgh, PA, June 2004.

Yan, et al., Cost and performance design approach for GTHTR300 power conversion system, Nucl. Eng. Design., pp. 351-373, 2003. 
Appendix A

\section{Lumped Parameter Representation} of Sulfur lodine Process 


\section{Appendix A}

\section{Lumped Parameter Representation of Sulfur lodine Process}

A reasonable first approximation for representing the heat load presented by the SI process at the interface has each of the three sections represented as a lumped region of mass that communicates with the other sections via mass and energy streams. A schematic is shown in Figure A-1. A mass balance on section i gives

$\frac{d M_{i}}{d t}=\delta_{1, i} \dot{m}_{H_{2} O}-\delta_{1, i} \dot{m}_{O_{2}}-\delta_{3, i} \dot{m}_{H_{2}}+\sum_{j \neq i} \dot{m}_{i, j_{0}} f_{j}-\dot{m}_{j, i_{0}} f_{i}, \mathrm{i}=1,2$, and 3

where

$$
\begin{aligned}
& M_{i}=\quad \text { mass in section } \mathrm{i} \text { (sum of all chemical species and structures) } \\
& \dot{m}_{i, j_{0}}=\quad \text { mass flowrate into section } \mathrm{i} \text { from section } \mathrm{j} \text { at full power condition, } \\
& f_{i}=\quad \begin{array}{l}
\text { net rate of heat production (or consumption) in section i as a consequence of chemical } \\
\text { reactions, expressed as a fraction of the value at full power condition, }
\end{array} \\
& \dot{m}_{\mathrm{H}_{2} \mathrm{O}}=\text { mass flowrate of water into SI process, } \\
& \dot{m}_{\mathrm{O}_{2}}=\text { mass flowrate of oxygen into SI process, and } \\
& \dot{m}_{H_{2}}=\quad \text { mass flowrate of hydrogen into SI process. }
\end{aligned}
$$

In writing the above equation it is assumed the mass flowrate of products leaving one section for another section equals the value for the plant at full power scaled by the present power of the section from which the materials are leaving, $f_{i}$. Here power is the net rate of heat input (or output) and is taken as a user-supplied forcing function. Section 1 is the Bunsen reaction, Section 2 is the sulfuric acid decomposition step, and Section 3 is the hydrogen iodine decomposition step.

An energy balance on section i gives

$$
\begin{array}{r}
\frac{d M_{i} C_{v_{i}} T_{i}}{d t}=\delta_{1, i} \dot{m}_{H_{2} O} h_{H_{2} O}\left(T_{1}\right)-\delta_{1, i} \dot{m}_{O_{2}} h_{O_{2}}\left(T_{1}, P_{1}\right)-\delta_{3, i} \dot{m}_{H_{2}} h_{H_{2}}\left(T_{3}, P_{3}\right)+ \\
\sum_{j \neq i} \dot{m}_{i, j_{0}} h_{i, j_{0}}\left(T_{j}, P_{j}\right) f_{j}-\dot{m}_{j, i_{0}} h_{j, i_{0}}\left(T_{i}, P_{i}\right) f_{i}+Q_{i_{o}} f_{i} \\
\quad \mathrm{i}=1,2 \text {, and } 3
\end{array}
$$

where $h$ is specific enthalpy, $\mathrm{C}_{\mathrm{v}}$ is the chemical species/structures averaged constant-volume specific heat, and $\mathrm{Q}$ is the flowrate of heat into the section. It is assumed the energy flowrate of products leaving one section for another section equals the value for the plant at full power scaled by the present power of the 
section from which the materials are leaving, $f_{i}$. A separate log mean temperature model for the heat exchanger couples $Q_{i_{o}} f_{i}$ to the reactor system through temperatures and flowrates. The subscript $o$ denotes the full power condition.

This model assumes that water enters and oxygen leaves Section 1 at the temperature of the section which is near room temperature. The model does not represent recuperation of the heat stored in the hydrogen which leaves the cycle at the temperature of Section 3. The user also provides the water inflow and oxygen and hydrogen outflow rates and the pressures of the gases. An equation of state could be added in which case pressures would not be required input.

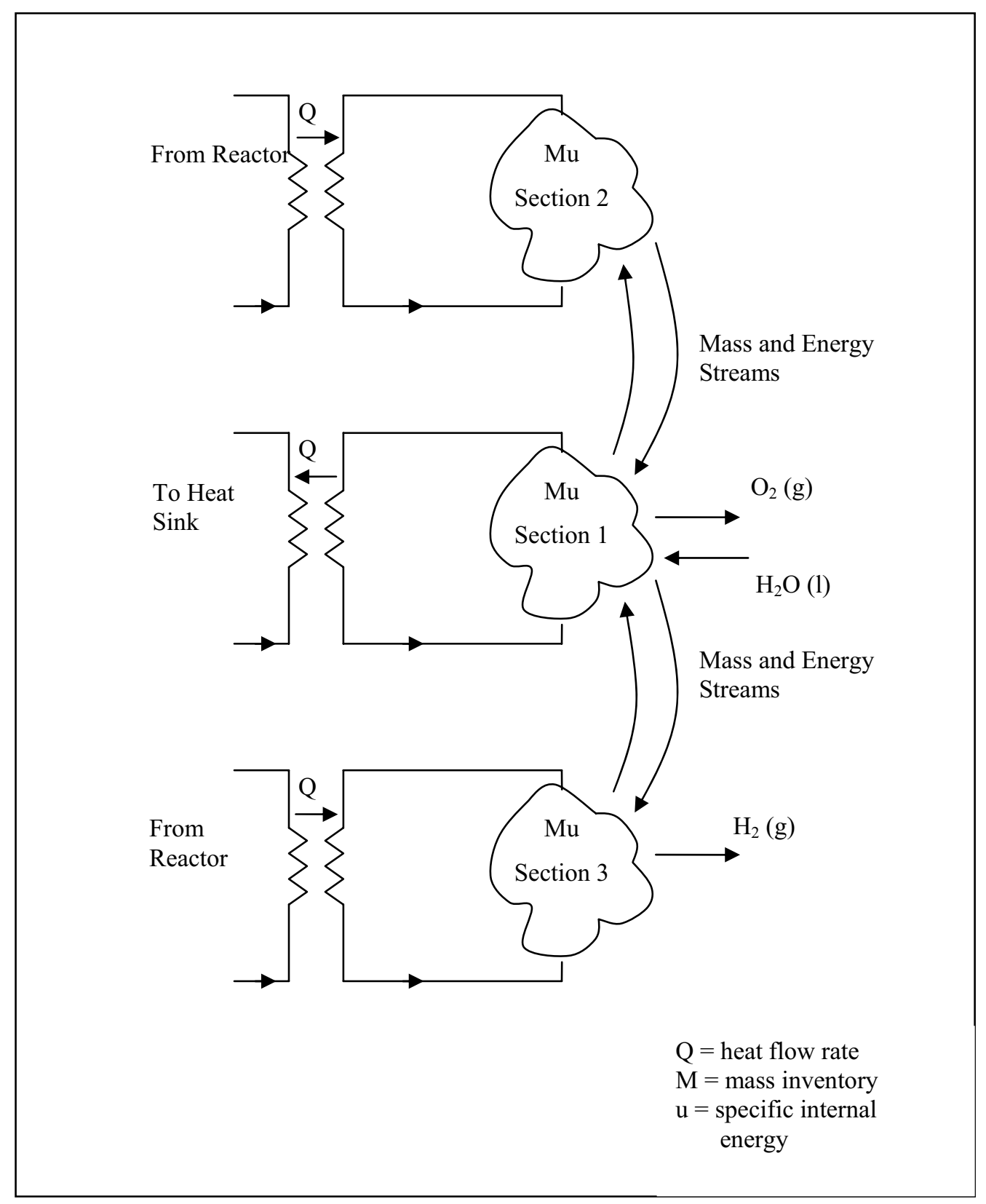

Figure A-1. Schematic of Energy and Mass Inventories and Flowpaths 
The model can be used to study energy and mass storage effects and their influence on the interface when the user knows a priori the rate at which the overall reaction in a section proceeds. This model is simplified and lacks the temperature and species concentration dependent feedbacks that control the rates of chemical reactions in each section. In place of these the user provides the fractional power in each of the sections as a function of time where it is then assumed that the energy and mass flowrates leaving the section for other sections scale with this. The model is useful then for studying the temperatures and heat loads that the interface heat transfer equipment must be designed for in the steady state as implied by the detailed chemical flowsheet. It is also useful for studying the dynamic behavior of the inventories of materials to ensure adequate buffering of temperatures between the chemical plant and the nuclear plant to temporary imbalances in power that develop in either the nuclear plant or one of the sections in the SI process. Such imbalances might result from control system or component failures or human error. 